\title{
EL RETRACTO DEL CONTRATO DE SERVICIOS EDUCACIONALES DE NIVEL SUPERIOR EN LA LEY CHILENA DE PROTECCIÓN A LOS CONSUMIDORES ${ }^{*}$
}

\section{HERNÁN QUiroz VALENZUELA*}

RESUMEN: Este artículo analiza los fundamentos y las características del derecho que se establece en la ley chilena sobre protección a los derechos de los consumidores, para desistirse en forma unilateral y sin expresión de causa, de un contrato con un establecimiento de educación superior. Se postula que la justificación de este desistimiento difiere de aquellas que generalmente se proponen para dar una protección especial a los consumidores, y está relacionada con el sistema chileno de acceso a los estudios formales de nivel superior. Ese telón de fondo también explica sus requisitos y sus efectos. Apartándose de las tesis que explican su naturaleza jurídica como una condición resolutoria o una ineficacia sobrevenida, o como un incumplimiento lícito reconocido legislativamente, se propone que es un mecanismo previsto por la ley para impedir que nazca un contrato, por el ejercicio de una facultad que se confiere a una de las partes, que integra el marco jurídico en el que se forma el consentimiento de los contratantes, y garantiza la libertad de los alumnos para elegir.

PALABRAS CLAVE: Desistimiento - retracto - consumidor - educación superior - protección a los consumidores

\section{THE UNILATERAL RENOUNCEMENT OF THE HIGHER EDUCATION SERVICES CONTRACT UNDER THE CHILEAN LAW OF CONSUMER'S PROTECTION}

ABSTRACT: This article will analyze the grounds and the general characteristics of the protection of the consumers' rights set forth in the Chilean legislation. More specifically, the consumer's faculty to waive

Fecha de recepción: 24 de septiembre de 2015.

Fecha de aceptación: 4 de abril de 2016.

** Licenciado en Ciencias Jurídicas y Sociales de la Universidad de Chile (Chile), Postgrado en Administración de Empresas de la P. Universidad Católica de Chile (CHILE), Magíster en Derecho privado y alumno del programa de Doctorado en Derecho de la Universidad de los Andes (CHILE). Correo electrónico: hquiroz@miuandes.cl 
unilaterally, and without justification, his rights granted by a contract executed with a university or another institution of such nature. It is stated that the justification of this right is probably different from those usually proposed to provide the consumers with a special protection. In consequence, its legal justification shall be found in the context of the systems applied in Chile to access higher level formal studies. This background also explains its requirements and legal effects/consequences. Moving away from the thesis explaining the legal nature of the matter in discussion as a resolutory condition, or a sudden ineffectiveness, or even as a lawful non-compliance, it is actually proposed as a mechanism provided by law, which permits to avoid the birth of a contract. According to the law, the faculty in comment assures a single party's (the student) right to choose.

KEYWORDS: Unilateral renouncement - consumer - higher education - consumer's protection

Sumario: I. Fuente legal, contexto y fundamentos de la institución 1) Objeto de este estudio. 2) Antecedentes legislativos y texto legal. 3) Contexto y finalidad del retracto educacional. 4) Razones de la protección del alumno retrayente. 5) El retracto en la legislación educacional. II. Noción, titularidad, requisitos y forma de ejercicio. 1) Noción. 2) Titularidad o legitimación activa. (2.1.) El alumno. (2.2.) El "representante" del alumno. (2.3.) ¿Es el retrayente un consumidor o un usuario? 3) Requisitos. (3.1.) Solicitud expresa ante la respectiva institución. (3.2.) Acreditación de segunda matrícula. (3.3.) Ejercicio dentro del plazo legal. 4) Forma de ejercicio. IV. Efectos del retracto educacional. 1) Ineficacia contractual. (1.1.) ¿Cumplimiento de una condición resolutoria meramente potestativa? (1.2.) ¿Incumplimiento licito? (1.3.) Nuestra opinión: requisito necesario para la formación del consentimiento contractual. 2) Prohibición de retener dinero o documentos de pago o crédito y obligación de restituirlos. 3) Revocación de mandatos 4) Derecho a retención de parte de la matricula. 5) Derecho a cobrar servicios prestados. Conclusiones. Bibliografia citada.

\section{FUENTE LEGAL, CONTEXTO Y FUNDAMENTOS DE LA INSTITUCIÓN}

\section{1) OBJETO DE ESTE ESTUdIO}

El interés por comprender el sentido y el alcance del derecho de desistimiento o retracto en el contrato de prestación de servicios educacionales surge al constatar, por una parte, su originalidad como una institución del derecho nacional de protección a los consumidores, y, por otra, la importancia práctica que ella tiene dentro de nuestro sistema de selección de postulantes a la educación superior. 
En nuestro derecho de obligaciones y en particular en materia de protección a los consumidores, la carga que pesa sobre un proveedor, de dar o hacer aquello que es objeto de la obligación que ha contraído con el consumidor, constituye su deber primario, y tiene su causa $-y$ por ende su justificación- en el deber correlativo del consumidor de pagar el precio del bien o servicio de que se trate.

En Chile, el principio orientador en el derecho privado es el deber, que pesa sobre ambas partes de un contrato bilateral, de cumplir lo pactado, en la forma convenida. Este principio se conoce universalmente como pacta sunt servanda -lo pactado obliga-, y está recogido en el artículo 1545 del Código Civil chileno, que dice que todo contrato legalmente celebrado "es una ley para los contratantes, y no puede ser invalidado sino por su consentimiento mutuo o por causas legales". Por tratarse de un principio general en nuestra legislación, tanto las partes como el juez deben interpretar las normas jurídicas de un modo que se conforme a esta regla general.

La Ley No 19.496, sobre Protección de los Derechos de los Consumidores, publicada en el Diario Oficial el 7 de marzo de 1997, confirma la validez de este principio en la letra a) de su artículo 16. Según esta disposición, "la facultad de dejar sin efecto o modificar a su solo arbitrio el contrato o de suspender unilateralmente su ejecución" no puede producir efectos, a menos que se convenga en favor del consumidor, y ni siquiera se admite esa posibilidad con carácter general, sino únicamente para el comprador en ciertos contratos de compraventa, y, obviamente, sin perjuicio de las excepciones que esta $\mathrm{u}$ otras leyes contemplen ${ }^{1}$. Las normas que definen una cláusula como abusiva son de orden público, por lo que las partes no pueden pactarlas en sus contratos, ni modificar sus efectos.

Hemos querido centrar nuestro estudio en una de esas situaciones excepcionales, la retractación en el contrato educacional de nivel superior, porque es un elemento central de uno de los sectores regulados de mayor relevancia en Chile -el de la educación formal-, que es desconocido en otros sistemas legales, y porque su regulación presenta una configuración singularísima, si le compara con otras formas de retracto que admite

1 El Art. 16 letra a) de la LPC fue tomado de la Ley espańola 26/1984, de 19 de julio, General para la Defensa de los Consumidores y Usuarios (BOE-A-1984-16737), hoy derogada y refundida por el Real Decreto legislativo 1/2007 (BOE A-2007-20555). En su artículo $10^{\circ}$, esta ley establecía que las cláusulas, condiciones o estipulaciones que, con carácter general, se aplicarán a la oferta, promoción o venta de productos o servicios, deberían cumplir, entre otros requisitos, con la buena fe y justo equilibrio de las contraprestaciones lo que, entre otras cosas, excluía, conforme al № 2 de la letra c) de ese artículo, "Las cláusulas que otorguen a una de las partes la facultad de resolver discrecionalmente el contrato, excepto, en su caso, las reconocidas al comprador en las modalidades de venta por correo, a domicilio y por muestrario". 
nuestra legislación ${ }^{2}$; o incluso con las otras causales de desistimiento unilateral que la propia LPC admite, a favor del comprador a distancia, en ciertos contratos celebrados a través de internet (Art. $3^{\circ}$ bis), y respecto de ciertos servicios financieros (Art.17 D).

\section{2) ANTECEDENTES LEGISLATIVOS Y TEXTO LEGAL}

La falta de una noción sobre el retracto en la LPC hace necesario un esfuerzo de investigación para determinar el contenido de este derecho y desentrañar su significado, y recurrir en primer lugar, como nos indican las reglas de interpretación, a la historia fidedigna de su establecimiento (Art. 19 CC).

El retracto del consumidor no se consideró en el texto original de la LPC. Fue introducido por la Ley No 19.955, de 2004, para determinados casos, que se describen en los artículos $3^{\circ}$ bis y $3^{\circ}$ ter. El Art. 3 ter reguló el llamado "retracto educacional". La Ley No 20.555, de 2011, agregó un nuevo supuesto de retracto en el artículo $17 \mathrm{D}$.

El mensaje presidencial con que se inició, en 2001, la tramitación de Ley No 19.955 en la Cámara de Diputados ${ }^{3}$, señalaba que el proyecto "consagra el derecho de retracto, común en otras legislaciones" 4 , y lo definía como "la facultad del consumidor, en los casos específicos que se señalan, para desistirse del contrato en un plazo determinado, sin expresión de causa". Agregaba que "Este derecho se contempla para situaciones en que los espacios de formación del consentimiento aparecen debilitados frente a técnicas de comercialización agresivas" 5 . Observemos que la LPC emplea la expresión "derecho de retracto", sin embargo, el derecho civil español y las doctrinas comparadas usan otras denominaciones, y la que se emplea con mayor frecuencia es "desistimiento" 6 .

2 Algunos casos de desistimiento de una de las partes pueden encontrarse en el Código Civil a propósito de la venta con arras (Art. 1804), del mandato (Art. 2124 inciso 3) y del contrato de sociedad (arts. 2065 y 2108).

3 Nos referimos al Mensaje 178-344, de 8 de septiembre de 2001.

4 Es importante precisar, que, en rigor, tal facultad no era entonces, ni es ahora, frecuente en la legislación comparada, al menos en las leyes que sirvieron de modelo a la nuestra; las leyes española, mexicana, argentina y uruguaya no lo contemplaban entonces, ni lo hacían las Directivas europeas, de evidente influencia en esas legislaciones.

5 Mensaje 178-344, de 8 de septiembre de 2001, del Presidente de la República, con que se inició el proyecto de dicha ley, que modificó la Ley $\mathrm{N}^{\circ} 19.496$, sobre Protección a los derechos de los Consumidores.

6 Beluche Rincón, Iris (2009) El derecho de desistimiento del consumidor. Valencia: Editorial Tirant lo Blanch, 104 pp., p. 22; Prado López, Pamela (2003) “Artículo 3o bis". En De la Maza Gazmuri, Ińigo y Pizarro Wilson, Carlos (directores) y Barrientos Camus, Francisca (coordinadora): La Protección de los Derechos de los Consumidores, Santiago: Thomson Reuters, pp. 152-164, p. 156. 
El retracto educacional no figuraba en el proyecto de la Ley $\mathrm{N}^{\circ}$ 19.955. Fue introducido durante su discusión en la Cámara de Diputados, por una indicación promovida por el diputado Eugenio Tuma, para otorgar este derecho en los contratos de servicios educacionales de nivel superior, entendiendo por tales los que prestan los centros de formación técnica, los institutos profesionales y las universidades.

La historia legislativa de este artículo es breve, si se la compara con la de los retractos a que se refieren los artículos $3^{\circ}$ bis. y $17 \mathrm{D}$. De hecho, los criterios interpretativos que quedaron definidos en el Informe de la Comisión de Economía del Senado, recaído en el proyecto de la Ley $\mathrm{N}^{\circ}$ 19.955 , solo se refieren al artículo $3^{\circ}$ bis. No hay en las actas de la discusión parlamentaria antecedentes que arrojen luz sobre las razones que se tuvieron para incorporar el retracto en los contratos de servicios educacionales en la LPC, si bien la manera en que se concibió originalmente difería en forma importante de cómo se aprobó en definitiva. La indicación presentada por el Diputado Tuma contenía una completa regulación, pero con plazos diferentes ${ }^{7}$. La Comisión aprobó unánimemente la norma.

No obstante, durante su discusión en el Senado, se presentaron indicaciones que buscaban suprimirla o modificar su texto ${ }^{8}$. La que fue aprobada tenía diferencias menores con la propuesta original: el plazo de retracto se reducía a diez días corridos y se contaba desde la publicación de la nómina de los aceptados en las universidades que integran el Consejo de Rectores; permitía al establecimiento educacional retener la matrícula y hasta una mensualidad, en caso que el alumno se retirara una vez iniciado el período académico, y exigía como condición para el retrac-

$7 \quad$ Su texto era del siguiente tenor: "En el caso de prestaciones de Servicios Educacionales de nivel Superior, incluido en ellos los Centros de Formación Técnica, Institutos Profesionales y Universidades, se faculta al consumidor o a quien efectúe el pago en su representación para que, dentro de los primeros treinta días corridos contados desde el inicio de la prestación del servicio, proceda a dejar sin efecto el contrato con la respectiva institución, sin pago alguno por los servicios educacionales no prestados. Se entenderá que no corresponde ningún pago si el consumidor deja sin efecto el contrato antes del inicio del período académico respectivo. No obstante, la Institución estará facultada a cobrar hasta una mensualidad, además de la matrícula, en el caso de que el retiro del alumno se produzca dentro de los primeros treinta días del período académico. En ningún caso, la Institución podrá retener los documentos de pago posterior a este retracto, ya sea, letra, pagaré o cheque, otorgados en respaldo del período educacional respectivo. En el caso de haberse otorgado mandato general para hacer futuros cobros, este se anulará con la sola renuncia efectiva del consumidor al servicio educacional. El prestador del servicio se abstendrá de negociar o endosar los documentos recibidos antes del plazo seńalado en el inciso $20^{\circ}$ ".

8 La indicación 28a , de los senadores Chadwick y Novoa, propuso suprimir esta norma y fue rechazada con los votos de los senadores Gazmuri, Lavandero y Orpis. En subsidio de esta indicación, los Sres. Chadwick y Novoa formularon la indicación 29a , para reemplazar el Art. $3^{\circ}$ ter. La indicación $30^{\mathrm{a}}$, presentada por el senador Romero, propuso sustituir, en el inciso $1^{\circ}$ del Art. $3^{\circ}$ ter, la frase que indicaba el momento inicial del cómputo del plazo para retractarse en estos contratos. Fue rechazada por los senadores Gazmuri, Novoa y Orpis. 
to que el consumidor estuviera inscrito en otra institución de educación superior y acreditara ese hecho. La indicación fue aprobada por la Comisión legislativa, pero se precisó que sería el alumno el primer llamado a ejercer el retracto, y que el plazo de diez días se contaría desde la primera publicación de los resultados de las postulaciones a universidades pertenecientes al Consejo de Rectores; que la condición para el retracto sería más exigente, pues requería ser alumno de primer ańo de una carrera o programa de pregrado; prohibía también retener los dineros y documentos de pago posteriores al retracto y obligaba a restituirlos dentro de diez días. Se estableció, finalmente, que la revocación del mandato general para cobrar operaría por el solo ministerio de la ley, y se repuso la facultad de la entidad prestadora de retener del valor de la matrícula, en compensación de sus costos de administración, hasta el 1\% del arancel anual del programa o carrera.

La Comisión de Economía del Senado aprobó el texto en las sesiones de 9 y 16 de diciembre de 2003 y de 13 de enero y de 2 de marzo de 2004. No tuvo más modificaciones y en definitiva se convirtió en ley, con el siguiente texto:

"Artículo $3^{\circ}$ ter.- En el caso de prestaciones de servicios educacionales de nivel superior, proporcionadas por centros de formación técnica, institutos profesionales y universidades, se faculta al alumno o a quien efectúe el pago en su representación para que, dentro del plazo de diez dias contados desde aquél en que se complete la primera publicación de los resultados de las postulaciones a las universidades pertenecientes al Consejo de Rectores de las Universidades Chilenas, deje sin efecto el contrato con la respectiva institución, sin pago alguno por los servicios educacionales no prestados.

"Para hacer efectivo el retracto a que se refiere este articulo, se requerirá ser alumno de primer año de una carrera o programa de pregrado y acreditar, ante la institución respecto de la cual se ejerce esta facultad, encontrarse matriculado en otra entidad de educación superior.

"En ningún caso la institución educacional podrá retener con posterioridad a este retracto los dineros pagados ni los documentos de pago o crédito otorgados en respaldo del periodo educacional respectivo, debiendo devolverlos todos en el plazo de 10 dias desde que se ejerza el derecho a retracto. En el evento de haberse otorgado mandato general para hacer futuros cobros, este quedará revocado por el solo ministerio de la ley desde la fecha de la renuncia efectiva del alumno al servicio educacional. El prestador del servicio se abstendrá de negociar o endosar los documentos recibidos, antes del plazo señalado en el inciso primero.

"No obstante lo dispuesto en el inciso anterior, la institución de educación superior estará facultada para retener, por concepto de costos de administración, un monto de la matricula, que no podrá exceder al uno por ciento del arancel anual del programa o carrera". 
Como vemos, los antecedentes legislativos no son explícitos respecto de los motivos que justificaban esta institución, pero ello revela que su necesidad era obvia para todos y no necesitaba mayor explicación. Lo entenderemos si analizamos lo que sucedía en el sistema de educación superior chileno y el régimen de ingreso a las diversas carreras que imparten las instituciones que lo integran.

\section{3) CONTEXTO Y FINALIDAD DEL RETRACTO EDUCACIONAL}

Para comprender el retracto educacional previsto en el Art. 3 ter LPC hay que analizar la situación del sistema de educación superior chileno, que se ha ido conformando progresivamente y en varias etapas.

La primera que va desde la creación de la Universidad de Chile en 1842 hasta el ańo 1981; la segunda que va desde ese año al 2012, y la tercera del 2012 hasta nuestros días.

En la primera etapa se crearon varias universidades, algunas del Estado, otras de la Iglesia Católica, y otras de corporaciones privadas. En 1954, con las universidades existentes (8) se creó el Consejo de Rectores (ley No 11.575, Art. 36, letra c), al que se concedió personalidad jurídica en 1964 (ley No 15.561). El Estado aportaba fondos a estas universidades, tanto estatales como privadas. Este organismo creó un sistema unificado para que los estudiantes ingresaran a las carreras, mediante un examen de selección, denominado Prueba de Aptitud Académica (1967).

Este esquema vino a alterarse profundamente en 1981. A través de diversos cuerpos legales, se establecieron entonces tres tipos de instituciones de educación superior: las universidades, que podían ofrecer carreras a las que se exigía un grado académico de licenciado, los institutos profesionales, que podían impartir carreras para las que no se exigía grado académico, y los centros de formación técnica, que ofrecían carreras cortas que daban el título de técnico de nivel superior. La nueva legislación permitió, además, la creación de nuevas universidades privadas y convirtió en nuevas instituciones universitarias a las sedes regionales de las Universidades de Chile, Técnica del Estado y Católica de Santiago. Se establecieron también nuevas formas de aporte financiero del Estado, entre ellas, el Aporte Fiscal Indirecto, para las instituciones cuyos estudiantes obtuvieran altos puntajes en la Prueba de Aptitud Académica. En tanto, el CRUCH se amplió con la división de sus universidades, y tras varios cambios, quedó conformado por los rectores de 25 universidades: las 8 originales y sus derivadas?

9 El Consejo de Rectores agrupa a las 16 universidades estatales y a 9 privadas: U. de Chile, P. U. Católica de Chile, U. de Concepción, P. Católica de Valparaíso, U. Católica del Norte, U. Técnica Federico Santa María, U. de Santiago de Chile, Austral de Chile, U. de Valparaíso, U. Metropolitana de Ciencias de la Educación, Tecnológica Metropolitana, U. 
Desde 1981 se han creado en nuestro país múltiples universidades; ninguna de ellas forma parte del Consejo de Rectores. Para distinguir unas de otras se habla de universidades "tradicionales" (estatales y privadas, originarias y derivadas) que integran el Consejo de Rectores, ahora denominado CRUCH (sigla de Consejo de Rectores de las Universidades Chilenas) y universidades privadas no tradicionales que están fuera de dicho Consejo. También están excluidos del CRUCH los institutos profesionales y los centros de formación técnica.

El año 2003 el Consejo de Rectores acordó sustituir la Prueba de Aptitud Académica por otro test, que se denominó Prueba de Selección Universitaria (PSU). En este panorama pasaron a coexistir dos sistemas de ingreso a la educación superior. En primer lugar, el organizado por el Consejo de Rectores a través de la Prueba de Selección Universitaria, que pueden rendir todos los egresados de la educación media, denominado "sistema unificado"; en segundo lugar, el procedimiento que emplean las instituciones de enseñanza superior que no integran el CRUCH.

El sistema unificado funciona del siguiente modo: la prueba se rinde por escrito en el mes de diciembre de cada año. Algunas semanas después, se publican en internet los resultados con los puntajes de cada alumno. Con ese resultado, el alumno postula a un número de carreras, ordenándolas por su preferencia. Las vacantes para cada carrera están fijadas anticipadamente por las entidades educativas, que aceptan a los postulantes según el puntaje que obtuvieron en la PSU, y dejan en lista de espera, ordenados también según el puntaje obtenido en la PSU, a los que no pudieron superar el puntaje de corte, que es aquel con que se completa el número de cupos disponibles. Los resultados de esa postulación suelen darse a conocer los primeros días de enero; entonces los postulantes seleccionados en una carrera pueden matricularse en ella y los que han quedado en lista de espera pueden esperar un segundo llamado que se produce cuando alguno de los primitivamente aceptados no se matricula y deja así espacios no cubiertos. Ese segundo llamado suele darse en la segunda semana de enero.

La mayoría de las instituciones educativas que están fuera del Consejo de Rectores exige que sus postulantes rindan la PSU y los seleccionan en función del puntaje que han alcanzado en ese examen. En esta estrategia de selección influye el incentivo económico del Aporte Fiscal Indirecto, que introduce un elemento de competencia a las instituciones de educación superior, por captar a los estudiantes con mejores puntajes en la PSU.

Debe advertirse que, desde 1981 en adelante, en general, las instituciones de educación superior -estatales y privadas-, cobran a sus alumnos

de Tarapacá, Arturo Prat, U. de Antofagasta, U. de La Serena, U. de Playa Ancha, U. de Atacama, U. del Bío-Bío, U. de La Frontera U. de Magallanes, U. de Talca, U. Católica del Maule, U. Católica de la Santísima Concepción y U. Católica de Temuco. 
una cantidad al matricularse en su carrera, y luego un arancel mensual. Los alumnos que no pueden pagarlos pueden optar a becas o a un crédito universitario con tasas rebajadas y pagadero al egreso.

Con estos dos sistemas de ingreso paralelos, desde la década de los ochenta del siglo pasado las instituciones que no estaban en el sistema unificado, comenzaron a aceptar alumnos desde el mismo día en que se publicaban los puntajes de la PSU, y antes de que se conocieran los resultados del proceso de postulación de las universidades del CRUCH,y, entonces, comenzó a producirse un problema económico que afectaba a las familias de los postulantes, porque, mientras el alumno estaba en la incertidumbre acerca de si su puntaje obtenido le permitiría quedar seleccionado en la carrera que le interesaba de alguna universidad tradicional, debía decidir entre matricularse o no en alguna universidad no tradicional que también le interesaba, y que no lo podía esperar porque necesitaba llenar sus vacantes. Así las cosas, si no aseguraba un cupo en una universidad no tradicional, corría el peligro de que cuando llegara a postular después de haberse concluido el proceso de selección en las universidades del Consejo de Rectores, ya estuvieran copadas las vacantes en la universidad privada no tradicional que tenía como segunda opción. Enfrentada a este dilema, su familia optaba por asegurar un cupo en la universidad no tradicional.

A su vez, la universidad privada aceptaba al alumno pero siempre que se matriculara, lo cual significaba pagar un cantidad de dinero junto con la matrícula y que su padre o algún adulto que actuara como apoderado garantizara, mediante contrato e instrumentos de crédito (pagarés, letras de cambio) el pago del arancel por el total del semestre o año, según la carrera. Se producía así el caso en que muchos alumnos se matriculaban, para asegurar su segunda opción, en una institución privada no tradicional, pero luego quedaban seleccionados por una universidad del Consejo de Rectores en la carrera de su preferencia. De esta forma, acudían a la primera universidad para pedir que les restituyeran lo pagado por la matrícula y sobre todo que se dejaran sin efecto los instrumentos que garantizaban el pago del arancel. Un cierto número de estas universidades, sin embargo, se negaba a acceder a esta petición y alegaba que se les debía pagar todo el arancel porque ya no podían ocupar la vacante que había sido asegurada al alumno que ahora quería desistirse.

Es este el problema que vino a solucionar el retracto regulado en el Art. 3 ter LPC, y sobre esta base se hacen comprensibles sus requisitos y sus efectos ${ }^{10}$. Así se entiende por qué el plazo para hacer efectivo este de-

10 "Este artículo -observa Pizarro- viene a solucionar un problema presente desde hace un tiempo en las postulaciones a los establecimientos de educación superior. Con el objeto de "atrapar" los estudiantes, las universidades procedían a cerrar las matrículas en un período durante el cual todavía podían presentarse modificaciones importantes en las listas de espera. Esto significaba colocar al estudiante en la situación de decidir por un establecimiento en particular aun existiendo posibilidades de matricularse en otro de su preferencia. Ahora el futuro estudiante 
recho comienza a correr después de la publicación de las postulaciones a las universidades pertenecientes al CRUCH, y por qué se ejerce exhibiendo el comprobante de otra matrícula.

La tercera etapa ha mitigado parcialmente este problema. En 2012 el Consejo de Rectores invitó a adherirse a su sistema de selección a algunas universidades privadas "no tradicionales", con tal que aceptaran sus reglas de postulación, vacantes e intercambio de información. Ocho establecimientos aceptaron ingresar al sistema, que funcionó de esta manera por primera vez en 2013 ${ }^{11}$. En 2016 el CRUCH aceptó el ingreso al sistema de una novena universidad y evalúa algunas que lo han solicitado formalmente. De esta manera, el dilema arriba descrito sigue planteándose entre las instituciones que forman parte del proceso unificado de selección (las 25 universidades miembros del CRUCH y las 9 adscritas al proceso de selección), y las 26 universidades, 43 institutos profesionales y 58 centros de formación técnica que son ajenas a él ${ }^{12}$.

Aunque no hemos encontrado cifras oficiales sobre la evolución del retracto educacional en los últimos años ${ }^{13}$, alguna evidencia empírica ${ }^{14}$ sugiere que, desde entonces, el retracto unilateral quedó limi-

podrá ejercer el retracto dentro de los diez días siguientes a la publicación de los resultados de las postulaciones a las universidades tradicionales. Eso sí, el alumno matriculado deberá acreditar que optó por otro establecimiento educacional, debiendo acreditar esta circunstancia y que se encuentra matriculado en otra entidad de educación superior". Pizarro Wilson, Carlos (2012) "El incumplimiento lícito del contrato por el consumidor: "el Derecho de Retracto”. En De la Maza Gazmuri, Ińigo y Pizarro Wilson, Carlos (directores) y Barrientos Camus, Francisca (coordinadora): La Protección de los Derechos de los Consumidores. Santiago: Thomson Reuters, pp. 235-247, p. 245.

11 Las universidades adscritas al proceso de admisión del CRUCH son las siguientes: Alberto Hurtado, Diego Portales, Mayor, Finis Terrae, Andrés Bello, de los Andes, Adolfo Ibáñez, del Desarrollo y Católica Silva Henríquez (a partir del proceso de admisión de 2017). SIES (2014) "Panorama de la Educación Superior en Chile 2014. División de Educación Superior, Ministerio de Educación”. Estudio publicado por el Servicio de Información de Educación Superior (SIES), del Ministerio de Educación. Disponible en: http://www. mifuturo.cl / images/ Estudios / Estudios_SIES_DIVESUP/panorama_de_la_educacion_ superior_2014_sies.pdf. [fecha de visita: 24 de septiembre de 2015].

13 Al preparar este artículo hicimos una consulta formal al Jefe de la División de Educación Superior del Ministerio de Educación, acerca de las cifras que ese organismo posee, su evolución ascendente o descendente y reclamos recibidos en los últimos 5 años relativos al ejercicio del derecho de retracto que establece el artículo 3 ter de la Ley No 19.496. La respuesta a esta consulta nos fue remitida a través del oficio ordinario No 06/003481, de 22 de septiembre de 2014; en ella esa autoridad señala que ha consultado al Servicio Nacional de Información de la Educación Superior, que depende de esa División de Educación Superior, y constató que no existen bases de datos, ni información alguna, referente a estadísticas sobre el ejercicio del derecho de retracto que poseen los estudiantes que se matriculan en instituciones de educación superior. Añade que la Unidad de Regulación de esa misma División, le informó que no registra denuncias por incumplimiento al citado artículo $3^{\circ}$ ter.

14 La eficacia práctica del retracto educacional ha sido recogida en la memoria -inédita-, de Camila Lorca Cisternas, para optar al grado de Licenciado en Ciencias Jurídicas y Sociales, de la Facultad de Ciencias Jurídicas y Sociales de la Universidad Austral, titulada Ámbito 
tado a los institutos profesionales, a los centros de formación técnica y a las universidades que, por diferentes motivos, no participan de este sistema común de selección para el ingreso a la educación superior, y aceptan a sus postulantes en forma independiente del proceso de matrícula de las demás instituciones.

Cabe observar que es en esos establecimientos en donde se comprende la mayor parte de los estudiantes chilenos que cursan estudios de nivel superior ${ }^{15}$. Aclarado lo anterior, podemos responder a la razón de proteger a los alumnos mediante este derecho singular que es el retracto contractual.

\section{4) RAZONES DE LA PROTECCIÓN DEL ALUMNO RETRAYENTE}

Para buena parte de nuestra doctrina, la existencia misma de la LPC se justifica, generalmente, en la desigualdad que suele caracterizar a la posición negociadora de las partes de una relación de consumo, causada por las ventajas que, en términos de información, se atribuye a una de las partes -el proveedor- sobre la otra -el consumidor- ${ }^{16}$, lo que trae consigo la necesidad de corregir, como dice el profesor Aimone, la "asimetría de las partes en el conocimiento que tienen sobre la cosa debida en la relación jurídica que denominamos "relación de consumo"17. Una línea similar se observa en la legislación de nuestros países vecinos, como el nuevo Código de Protección y Defensa del Consumidor del Perú, de singular calidad técnica ${ }^{18}$. En esta línea deberíamos inscribir, entonces, al retrayente que ampara el Art. $3^{\circ}$ ter de la LPC.

de aplicación del Derecho de Retracto en la Ley No 19.496 de Protección al Consumidor, 2012, pp 23 y ss. Presenta un análisis del retracto en la prestación de servicios educacionales de nivel superior, a partir de un estudio sobre su aplicación práctica por estudiantes de las principales universidades valdivianas -Universidad Austral de Chile, Universidad San Sebastián y Universidad Tecnológica de Chile-, a fin de determinar cuán utilizado es este derecho y su sujeción la regulación legal, y concluye que todas ellas aceptan el retracto en los términos que establece el artículo $3^{\circ}$ ter de la LPC.

15 Ver Rolando M., Rodrigo, Salamanca V., Juan y Aliaga Q., Marcelo (2010) Evolución de la Matrícula de Educación Superior en Chile. Periodo 1990-2009. Santiago: Estudio publicado por SIES, División de Educación Superior, Ministerio de Educación, 29 pp., pp. 7 y ss.

16 Sandoval López, Ricardo (2004) Derecho del Consumidor. Protección del consumidor en la ley $N^{o}$ 19.496, de 1997 modificada por la ley $N^{o}$ 19.955, de 14 julio de 2004, y en la legislación comparada. Santiago: Editorial Jurídica de Chile, 247 pp., p. 71.

17 "Asimetría" quiere decir diferencia, disimilitud, diversidad. ¿De qué? La respuesta es que se trata de asimetría de información, lo que se transforma en distinto poder de mercado". Aimone Gibson, Enrique (2013) Derecho de Protección al Consumidor. Santiago: LegalPublishing, 203 pp., pp. 3 y 5.

18 Rige en ese país desde octubre de 2010. Su artículo II señala que tiene "la finalidad de que los consumidores accedan a productos y servicios idóneos y que gocen de los derechos y los mecanismos efectivos para su protección, reduciendo la asimetría informativa, corrigiendo, previniendo o eliminando las conductas y prácticas que afecten sus legítimos intereses". 
De la Maza propone que la protección especial a los consumidores se justificaría no solo porque el proveedor no suministre la información necesaria, sino también por "problemas de racionalidad imperfecta"; y afirma que "El problema no consistiría, únicamente, en que el consumidor no disponga de acceso a la información que le permita una adecuada formación del consentimiento, sino que, aun disponiendo de dicho acceso, no necesariamente es capaz de utilizar la información adecuadamente". Este autor encuentra precisamente aquí el fundamento de la facultad de retracto en favor del consumidor. "La causa más compleja que explica la presencia de asimetrías informativas es la racionalidad imperfecta. A diferencia de la falta de suministro de información, en este supuesto el consumidor tiene acceso a ella, sin embargo no es capaz de hacer un uso adecuado de la misma"; y añade: "Como sucede con las cláusulas abusivas de la lista negra, la justificación en los supuestos en que se autoriza el desistimiento no se relaciona necesariamente con la falta de información -la cláusula puede privarse de eficacia aun cuando el consumidor la haya conocido-, el consumidor puede desvincularse del contrato aun cuando se le haya suministrado toda la información pertinente, sino con problemas de racionalidad imperfecta del consumidor, este no resulta capaz de evaluar adecuadamente la cláusula o el bien o servicio que está adquiriendo"19.

En nuestro parecer esto no puede aplicarse al llamado retracto educacional. Ni la asimetría en la información y ni la insuficiencia cognitiva que se atribuye a los consumidores, bastan para explicar la protección que la LPC confiere a los sujetos beneficiados por esta forma tan especial de retracto. Aquí el retrayente puede estar perfectamente informado del contrato que se propone celebrar con el establecimiento educacional y, siendo un alumno que ha pasado por un proceso de selección entre los mejores estudiantes del país, probablemente posee la inteligencia necesaria para comprender la carrera y el establecimiento que ha elegido.

Asimismo, la fragilidad intelectual del consumidor no es un motivo que nuestra LPC reconozca como un principio que justifique una protec-

El concepto de "Asimetría informativa" recorre todo este código. Lo define como la característica de la transacción comercial por la cual uno de los agentes, el proveedor, suele tener mayor y mejor información sobre los productos y servicios que ofrece en el mercado a los consumidores. Entre sus fundamentos, se encuentra el Principio de Corrección de la Asimetría que define (Art. V No 4) como "Las normas de protección al consumidor buscan corregir las distorsiones o malas prácticas generadas por la asimetría informativa o la situación de desequilibrio que se presente entre los proveedores y consumidores, sea en la contratación o en cualquier otra situación relevante, que coloquen a los segundos en una situación de desventaja respecto de los primeros al momento de actuar en el mercado".

19 De la Maza Gazmuri, Iñigo (2010) "El suministro de información como técnica de protección de los consumidores: los deberes precontractuales de información”. Revista de Derecho Universidad Católica del Norte, Año $17 \mathrm{~N}^{\circ}$ 2, pp. 21-52. Prado (2013) 157. 
ción especial. Así se desprende de la historia de la LPC y de los proyectos que han concluido en normas legales que se le han incorporado en el tiempo ${ }^{20}$. En este sentido, la reforma introducida en 2004 por la Ley No 19.955, contribuyó a definir los fundamentos para proteger a los consumidores a través de la LPC, y dejó atrás cualquier concepción acerca de la debilidad intrínseca del consumidor por el solo hecho de serlo. El Mensaje presidencial con que el proyecto de ley fue enviado al Congreso establecía, como primer objetivo de esa reforma a la Ley No 19.496, ampliar su ámbito de aplicación "convirtiéndola en norma general aplicable a todos los actos de consumo y supletoria de las leyes especiales relacionadas con la protección de los derechos de los consumidores, entregando facultades al Servicio Nacional del Consumidor para asumir su defensa, independiente de si el acto de consumo está regido por la Ley No 19.496 u otro cuerpo normativo" y ańadía "La ampliación referida se establece eliminando el carácter mixto del acto jurídico de consumo, vale decir, civil para el consumidor y mercantil para el proveedor. Por su parte, mantener la vigencia de las leyes especiales resulta conveniente, por cuanto ello da cuenta de la especificidad de distintos sectores y mercados" 21 . Esto fue desechado durante la tramitación parlamentaria.

Asimismo, la Ley No 19.955 incorporó a la LPC la siguiente regla, en su artículo $1^{\circ}$ : "No se considerarán proveedores las personas que posean un título profesional y ejerzan su actividad en forma independiente". Ante esta evidencia, es razonable plantear que si el fundamento de la existencia de una ley especial para proteger los derechos de los consumidores como es la LPC, fuese su incapacidad de contratar en una posición de equilibrio con su contraparte, entonces no se habría limitado su aplicación a los actos mixtos, dejando fuera de su ámbito un sinnúmero de situaciones en que puede haber tal desequilibrio, y no se habría excluido de la aplicación de esta ley la relación cliente - profesional, porque en los servicios profesionales muy probablemente existirá -en el convenio mismo y en los hechos- una desigualdad entre las partes ${ }^{22}$.

20 Al revisar las actas de la discusión parlamentaria, tanto de la Ley No 19.496 como de las reformas introducidas por las leyes 19.659, 19.955, 20.410, 20.543 y 20.555, observamos que, en la perspectiva del legislador chileno, la debilidad del consumidor que justifica su protección especial a través de la LPC se circunscribe a tres elementos de la relación de consumo: su conocimiento acerca del producto o del servicio ofrecido, la posibilidad que tiene de escoger con facilidad otro equivalente y la facultad de reclamar contra sus defectos.

21 Mensaje 178/344, del Ejecutivo a la Cámara de Diputados, de 8 de septiembre de 2001.

22 En nuestro ordenamiento jurídico la condición de profesional es, en general, un componente fundamental en la responsabilidad civil. Por ejemplo, en la acción redhibitoria, que es la concede la ley concede al comprador "para que se rescinda la venta o se rebaje proporcionalmente el precio por los vicios ocultos de la cosa vendida, raíz o mueble" (Art. 1857 CC) se consideran vicios redhibitorios los que reúnen, entre otras condiciones, la de no haber sido manifestados por el vendedor "y ser tales que el comprador haya podido ignorarlos sin negligencia grave de su parte, o tales que el comprador no haya podido 
El fundamento de la institución debe ser buscado en otro lugar. En principio, parece razonable hacer esta búsqueda en los precedentes o influencias que pueda tener en ordenamientos jurídicos extranjeros, sin embargo, debemos observar que, en el periodo en que se elaboró la Ley No 19.955 y se analizó la aplicación de esta forma de retracto en Chile, el desistimiento unilateral del consumidor existía en el derecho comparado, pero estaba previsto para situaciones muy diferentes de las hipótesis que considera nuestro artículo $3^{\circ} \operatorname{ter}^{23}$.

El desistimiento incausado del consumidor existía en el sistema comunitario europeo desde diciembre de 1985, con la Directiva 85/374/ CEE, del Consejo de Europa, que facultó a los consumidores para retirarse de manera unilateral, sin penalidad alguna, de un contrato negociado

fácilmente conocerlos en razón de su profesión u oficio" (Art. $1858 \mathrm{~N}^{\circ} 3$ CC). Y si el vendedor "conocía los vicios y no los declaró, o si los vicios eran tales que el vendedor haya debido conocerlos por razón de su profesión u oficio, será obligado, no solo a la restitución o la rebaja del precio, sino a la indemnización de perjuicios"; pero si el vendedor no conocía los vicios ni eran tales que por su profesión u oficio debiera conocerlos, "solo será obligado a la restitución o la rebaja del precio" (Art. 1861 CC). Una regla similar encontramos en el artículo 1928 inc. $4^{\circ}$ del Código de Bello, a propósito de la obligación del arrendador de librar al arrendatario de toda turbación o embarazo: "El arrendatario tendrá además derecho para que se le abonen los perjuicios, si las reparaciones procedieren de causa que existía ya al tiempo del contrato, y no era entonces conocida por el arrendatario, pero lo era por el arrendador, o era tal que el arrendador tuviese antecedentes para temerla, o debiese por su profesión conocerla" y en los artículos 1932 y 1933 CC, al regular el derecho del arrendatario a exigir la terminación del arrendamiento y aun a la rescisión del contrato, según los casos, si el mal estado o calidad de la cosa le impide hacer de ella el uso para que ha sido arrendada, dispone que tendrá, además, derecho para que se le indemnice el daño emergente, si el vicio de la cosa ha tenido una causa anterior al contrato "Y si el vicio era conocido del arrendador al tiempo del contrato, o si era tal que el arrendador debiera por los antecedentes preverlo o por su profesión conocerlo, se incluirá en la indemnización el lucro cesante".

23 Estas hipótesis de aplicación aparecen descritas en la obra de destacados autores de la madre patria. Puede consultarse, por ejemplo, Bermúdez Ballesteros, María del Sagrario (2001) "El Derecho de Desistimiento en materia de Viajes Combinados". Revista CESCO de Derecho de Consumo, No 2/2012. Centro de Estudios de Consumo Universidad de Castilla-La Mancha. Disponible en: http: // www. revista. uclm.es/i ndex.php/cesco, [fecha de visita: 29 de agosto de 2014]. Zurilla Cariñana, María Ángeles (2008) "Alcance y límites de la armonización del derecho de desistimiento en el texto refundido de la ley general para la defensa de consumidores y usuarios". Comentarios a la Ley de Consumidores, Centro de Estudio de Consumo. Universidad de Castilla La Mancha. Disponible en: https:/www. uclm.es/centro/cesco /pdf/ comentarios/11.pdf [fecha de visita: 29 de agosto de 2014]. Llorente San Segundo, Inmaculada (2013) "La adaptación de la normativa reguladora del derecho de desistimiento a las exigencia de la Directiva 2011/83/UE sobre derechos de los consumidores". Cuadernos de Derecho Transnacional (octubre 2013), Vol. 5, No 2, pp. 371-397. NúŃEZ Rodríguez, Erick (2012) El derecho de desistimiento: Especial consideración al desistimiento contractual, Universidad de Salamanca, Tesis de Doctorado, 432 pp. Disponible en: http://hdl.handle.net/10366/121398 [fecha de visita: 29 de agosto de 2014]. Bercovitz Rodríguez-Cano, Alberto (1978) "La protección de los consumidores, la Constitución española y el derecho mercantil". Lecturas sobre la Constitución Española. Madrid: Facultad de Derecho, Universidad Nacional a Distancia, Tomo II, pp. 9 a 37. 
fuera de un establecimiento mercantil, y obligar al proveedor, dentro de un plazo perentorio, a devolverle el precio del bien o servicio ${ }^{24}$. La extensión de ese derecho a la legislación interna de los países miembros de la Unión Europea, se concentró en las compras compulsivas, en ciertas transacciones electrónicas y en contratos de índole turística o de aprovechamiento por turno de bienes inmuebles ${ }^{25}$.

24 Ver Arts. $1^{\circ}$ y $4^{\circ}$ de la Directiva 85/374/CEE. La facultad del consumidor de "revocar su declaración de voluntad sin necesidad de alegar causa alguna, hasta pasados siete días contados desde la recepción", fue reconocida en España con la Ley 26/1991, derogada y refundida por el Real Decreto legislativo 1/2007, que aunque la estableció en amplios términos, restringió su aplicación a los contratos celebrados fuera de los establecimientos mercantiles. El fundamento último del sistema europeo de protección al consumidor se encuentra en el Tratado de Funcionamiento de la Unión Europea, que, en su versión original, fue suscrito en Roma en 1957, como Tratado constitutivo de la Comunidad Económica Europea, y que ha sido objeto de sucesivas reformas hasta el texto actual que resulta de los acuerdos establecidos en el Tratado de Lisboa, suscrito el 13 de diciembre de 2007. El sistema político que creó el TFUE considera la obligación de los estados miembros de la Unión de incorporar en su legislación interna los principios y normas previstos para ellos y adoptar oportunamente las disposiciones que dicten los órganos de esa organización supranacional.

25 Muchas de las disposiciones legales vigentes en España y que se refieren directamente a los consumidores, se explican por la subordinación de la Constitución española a las Directivas de la Unión Europea, y en la obligación del estado español, en su calidad de suscriptor del Tratado de Maastricht, de acatar estas directivas e incluso incorporar esas reglas a su legislación interna, y por el mandato de la Constitución española a los poderes públicos de dictar una legislación protectora de los consumidores que esté en armonía con los preceptos de esa constitución, que tiene una concepción del orden económico basada en el "Estado social"; su artículo 128, por ejemplo subordina toda la riqueza del país al "interés general" y contiene un reconocimiento de la iniciativa pública en la actividad económica mucho más amplio que el que admite nuestra Constitución. Diversos autores españoles han analizado la influencia práctica en la legislación tanto del mandato constitucional de protección a los derechos de los consumidores como de la obligación que emana del derecho comunitario de incorporar las Directivas a su ordenamiento interno. El Capítulo III de la Constitución española trata acerca de "los principios rectores de la política social y económica", y contiene una serie de disposiciones que configuran lo que se ha denominado "el Estado social" español. En ese mismo capítulo se encuentra el artículo 51.1 de la Constitución española, dispone que "Los poderes públicos garantizarán la defensa de los consumidores y usuarios, protegiendo, mediante procedimientos eficaces, la seguridad, la salud y los legítimos intereses económicos de los mismos”. Badenas Carpio, Juan Manuel y Boldó Roda, Carmen (2003) Régimen Juridico de la Llamada "Venta Directa". Las Ventas Domiciliarias y a Distancia. Valencia: Tirant lo Blanch, p. 13. 
Aunque en años recientes el retracto se ha admitido en legislaciones extranjeras del consumo con diversas modalidades -y bajo diferentes denominaciones-26, su regulación para el caso específico de los servicios de educación, dentro de la ley protectora de los derechos de los consumidores, es una institución original de la legislación chilena. Si orientamos nuestra búsqueda hacia el sistema chileno de obligaciones y en la inserción de los contratos de consumo dentro de este régimen, hemos de observar que el principio dominante es que el vínculo contractual no puede ser roto por la voluntad de una sola de las partes, y las "causas legales" en que se admite la retractación unilateral como causal de término de un contrato constituyen una calificada excepción. Además, en todos los casos de excepción a la regla general de la fuerza obligatoria del contrato, existe un claro fundamento que justifica la regla especial. Así, en la venta con arras el retracto se funda es la concepción de esta compraventa como afecta a una condición resolutoria, o a una posibilidad de cumplimiento alternativo, que las arras no vienen sino a reflejar ${ }^{27}$; y en el mandato, se funda en el componente de confianza que caracteriza esencialmente a la relación entre el mandante y el mandatario ${ }^{28}$.

La condición de excepcionalidad del retracto unilateral se repite en nuestra Ley No 19.496, no solo porque lo admite en caso específicos, sino porque, a propósito de las cláusulas abusivas que prohíbe en el artículo 16, se menciona, en el primer lugar, la prohibición del retracto. La letra a) este artículo dice que no producirán efecto alguno en los contratos de adhesión las cláusulas o estipulaciones que: "Otorguen a una de las partes la facultad de dejar sin efecto o modificar a su solo arbitrio el contrato o de suspender unilateralmente su ejecución, salvo cuando ella se conceda al comprador en las modalidades de venta por correo, a domicilio, por muestrario, usando medios audiovisuales, u otras análogas, y sin perjuicio de las excepciones que las leyes contemplen”. Esta disposición, tomada de la lista que contenía la Ley General de Consumidores y Usuarios es-

26 Ver nota 6.

27 Carvajal Ramírez, Patricio Ignacio (2006) “Las Arras en el Derecho Justinianeo”. Revista Chilena de Derecho, Pontificia Universidad Católica de Chile, Vol. 33 N 3, pp. 529-560. Estival Alonso, Luis (2006) El Contrato de Arras. Madrid: Difusión Jurídica y Temas de Actualidad S.A., 227 pp., p. 65.

28 Ver nota 3. Stichkin señala que, si bien el Art. 2124 del Código Civil autoriza al mandatario para retractarse, después de haber aceptado, ello constituye una calificada excepción a la regla general que lo obliga a cumplir el encargo, para evitar la responsabilidad que se deriva del incumplimiento, y que esta facultad de retractarse de la aceptación le permite exonerarse del cumplimiento siempre que no haya dado inicio a la ejecución. "Si ha dado inicio a la ejecución del encargo no puede retractarse de la aceptación, puesto que el contrato ya se ha realizado parcialmente". En tal caso cabe la renuncia sujeta "a ciertas condiciones e impone al mandatario cierta responsabilidad". Stitchkin Branover, David (1944) "El mandato civil”. Revista de Derecho, U. de Concepción, Año XII, No 49, p. 249. 
pañola ${ }^{29}$, prohíbe, como regla general, la facultad de retracto, concedida a cualquiera de las partes - no solo al proveedor-, excepto que se trate de algunos de los casos especiales que contempla la misma LPC, como el del vendedor a distancia, o ciertos contratos celebrados a través de internet, casos que, por ser excepcionales, deben interpretarse restrictivamente.

El retracto del consumidor, entonces, constituye también una calificada excepción al principio general del derecho privado conocido como pacta sunt servanda, lo pactado obliga, que en nuestro sistema recoge el artículo 1545 del Código Civil, aunque esta disposición admite, como una excepción a dicha regla general, que las partes pacten expresamente la posibilidad de dejar sin efecto el contrato, posibilidad que la LPC no contempla. Es posible que la idea de extender el retracto unilateral a los contratos de servicios educacionales haya sido tomada por nuestros legisladores de las normas comunitarias europeas sobre protección al consumidor, y particularmente del derecho español, porque estas fueron fuentes habituales de la Ley No 19.955; y que lo original de esta institución sea que se la haya extendido a los contratos de servicios educacionales; pero sin innovar en su carácter excepcional dentro del sistema de contratos.

Con todo, para comprender a cabalidad el fundamento de esta regla tan singular, hemos de vincularla con el régimen de selección de postulantes a la educación superior que se aplica en nuestro país. A la vista de este cuadro, creemos que es posible responder a la interrogante de por qué el Art. $3^{\circ}$ ter de la LPC otorga el derecho subjetivo, unilateral e incausado, de dejar sin efecto el contrato de educación de nivel superior,

29 Que prohíbe "La reserva a favor del profesional de facultades de interpretación o modificación unilateral del contrato sin motivos válidos especificados en el mismo, así como la de resolver anticipadamente un contrato con plazo determinado si al consumidor no se le reconoce la misma facultad o la de resolver en un plazo desproporcionadamente breve o sin previa notificación con antelación razonable un contrato por tiempo indefinido, salvo por incumplimiento del contrato o por motivos graves que alteren las circunstancias que motivaron la celebración del mismo". "En los contratos referidos a servicios financieros lo establecido en el párrafo anterior se entenderá sin perjuicio de las cláusulas por las que el prestador de servicios se reserve la facultad de modificar sin previo aviso el tipo de interés adeudado por el consumidor o al consumidor, así como el importe de otros gastos relacionados con los servicios financieros, cuando aquéllos se encuentren adaptados a un índice, siempre que se trate de índices legales y se describa el modo de variación del tipo, o en otros casos de razón válida, a condición de que el profesional esté obligado a informar de ello en el más breve plazo a los otros contratantes y estos puedan resolver inmediatamente el contrato. Igualmente podrán modificarse unilateralmente las condiciones de un contrato de duración indeterminada, siempre que el prestador de servicios financieros esté obligado a informar al consumidor con antelación razonable y este tenga la facultad de resolver el contrato, o, en su caso, rescindir unilateralmente sin previo aviso en el supuesto de razón válida, a condición de que el profesional informe de ello inmediatamente a los demás contratantes". "La autorización al profesional para rescindir el contrato discrecionalmente, si al consumidor no se le reconoce la misma facultad, o la posibilidad de que aquél se quede con las cantidades abonadas en concepto de prestaciones aun no efectuadas cuando sea él mismo quien rescinda el contrato". 
que ofrece una interpretación consistente con la finalidad de la norma y con su razonabilidad dentro de nuestro sistema de contratos, es plantearse otra pregunta: qué pasaría si esta institución no existiera tal como está concebida en esa disposición. Si esta institución no existiera, entonces el mecanismo con que opera el sistema de postulaciones a las entidades chilenas de educación superior no sería accesible para muchas familias, que quedarían comprometidas con el pago de todo el periodo de estudios programado por cada establecimiento en que el alumno se ha matriculado; $y$, si no existiera tal como está concebida en el Art. $3^{\circ}$ ter, entonces esos mismos establecimientos quedarían expuestos a perder lo que han invertido para ofrecer sus matrículas, y para estar listos para otorgar los servicios que constituyen su objeto, a los otros alumnos que opten por ellos ${ }^{30}$.

En consecuencia, el derecho de retracto que establece el Art. $3^{\circ}$ ter encuentra su justificación en el interés público de atender la situación en que se encuentran cada año muchos alumnos -y sus familias- que quieren ingresar a programas de pregrado, y que, ante la eventualidad de que no les resulte su postulación a alguna de las universidades del sistema de admisión regulado por el Consejo de Rectores, necesitan asegurar un cupo de segunda opción en alguna de las universidades, institutos profesionales y centros de formación técnica que no participan en ese proceso unificado.

Esto obedece a una combinación de factores que son propios del sistema chileno de acceso a la educación superior; bastaría con eliminar alguno de ellos para que, probablemente, esta institución cayera en desuso y, razonablemente, perdiera su justificación: un examen único de admisión; diferentes establecimientos que ofrecen esas carreras; la exigencia de un puntaje mínimo para postular y plazos distintos para hacerlo; la incertidumbre que ambas exigencias producen en los postulantes acerca de si serán aceptados en la carrera que desean; la mantención de esa incertidumbre hasta que concluyen los procesos de postulación; un régimen de estudios pagado en todas las instituciones de educación superior, incluso en las estatales; la consiguiente necesidad de las instituciones de financiarse mediante el cobro de los aranceles de cada carrera a los alumnos y, en el caso de las universidades, también con aportes fiscales indirectos, que subsidian la demanda premiando a las universidades que captan los puntajes más altos en la PSU, lo que conduce a que ellas compitan por matricular a los postulantes que han obtenido esos puntajes, y a que no puedan esperar a los que participan en distintos procesos de postulación, lo que trae consigo que ellos deban reservar un cupo pagando la matrícula y asumiendo la obligación de pagar el arancel de cada carrera en que se matriculan. 


\section{5) EL RETRACTO EN LA LEGISLACIÓN EDUCACIONAL}

El retracto educacional en Chile se contiene en el artículo $3^{\circ}$ ter de la LPC. Esta disposición define y regula los casos en que es posible, de manera unilateral, dejar sin efecto el contrato que ha de servir de causa a los servicios educacionales de nivel superior ${ }^{31}$. Sin embargo, para su aplicación debe tenerse en cuenta el artículo $2^{\circ}$ bis de la misma Ley, según el cual sus normas no se aplican a actividades de prestación de servicios "reguladas por leyes especiales", salvo en situaciones específicas en que prevalece la LPC, que el mismo Art. $2^{\circ}$ bis menciona, y la primera de ellas hace referencia a las materias que esas leyes especiales no prevean.

Esto tiene importancia en materia de retracto educacional, porque son especiales las normas legales que definen qué debe entenderse por servicios educacionales, por nivel superior, etc., y regulan también las obligaciones y responsabilidades especiales que son propias de esta actividad. Al entrar en vigencia nuestro artículo $3^{\circ}$ ter LPC, tales materias se regulaban en la Ley $\mathrm{N}^{\circ}$ 18.962, Orgánica Constitucional de Enseñanza ${ }^{32}$, el DFL 5, sobre Institutos Profesionales, de 6 de febrero de 1981; y el DFL 24, de 16 de abril de 1981, sobre Centros de Formación Técnica. Hoy están reguladas en la Ley No 20.129, de 2006, que creó el Sistema Nacional de Aseguramiento de la Calidad de la Educación Superior y en la Ley No 20.370, de 2009, General de Educación. Debe agregarse que el DFL No 2, del Ministerio de Educación, publicado en el Diario Oficial de 2 de julio de 2010, fijó el texto refundido, coordinado y sistematizado de la LEGE, con las normas no derogadas de la $\mathrm{LOCE}^{33}$.

La institucionalidad que se recoge en la legislación distingue entre educación superior no formal y formal; es en esta última donde tiene lugar el contrato de educación de nivel superior y por ende el retracto del que trata el Art. $3^{\circ}$ ter. La educación formal admite varias categorías o niveles, además de la educación de pregrado ${ }^{34}$, y reconoce, asimismo,

31 Brantt zumarán, María Graciela y Mejías Alonzo, Claudia (2013) "Artículo $3^{0}$ ter". En De la Maza Gazmuri, Ińigo y Pizarro Wilson, Carlos (directores) y Barrientos Camus, Francisca (coordinadora): La Protección de los Derechos de los Consumidores. Santiago: Thomson Reuters, pp. 183-189, p. 182.

32 Su texto refundido se estableció mediante el DFL No 1, del Ministerio de Educación, de 2005.

33 El Art. 70 transitorio de la LEGE, dispuso que "Sin perjuicio de lo señalado en el artículo siguiente, derógase el decreto con fuerza de ley $\mathrm{N}^{\circ} 1$, de 2005, del Ministerio de Educación, que fija el texto refundido, coordinado y sistematizado de la ley No 18.962, Orgánica Constitucional de Enseñanza, con excepción de lo dispuesto en el Título III, salvo su párrafo $2^{\circ}$, y en el Título IV”.

34 Según el Art. 17 de la LEGE, en Chile la educación formal o regular está organizada en cuatro niveles: parvularia, básica, media y superior, y por modalidades educativas dirigidas a atender a poblaciones específicas. Más adelante, en su artículo 21 señala que la Educación Superior es aquella que "tiene por objeto la preparación y formación del estudiante en un 
diferentes establecimientos legalmente habilitados para otorgarla. Además de las universidades, de los institutos profesionales y de los centros de formación técnica, se reconocen como instituciones de educación superior a la Academia Nacional de Estudios Políticos y Estratégicos; a las Academias de Guerra y Politécnicas; Escuelas de Armas y Especialidades de las Fuerzas Armadas; Escuela Técnica Aeronáutica de la Dirección General de Aeronáutica Civil; Academia de Ciencias Policiales de Carabineros de Chile; Escuelas Matrices de Oficiales de las Fuerzas Armadas; y Escuela de Suboficiales de Carabineros de Chile, y Escuela de Investigaciones Policiales e Instituto Superior de la Policía de Investigaciones de Chile ${ }^{35}$.

Ninguno de esos cuerpos legales especiales define el contrato de educación superior ${ }^{36}$. En general, este acto jurídico se expresa por medio de la matrícula misma, a falta de un contrato escrito ${ }^{37}$; por regla general, los términos contrato de educación superior y matricula son considerados como equivalentes ${ }^{38}$, y el uso indistinto de estas expresiones es precisamente lo que observamos en el Art. $3^{\circ}$ ter de la LPC.

nivel avanzado en las ciencias, las artes, las humanidades y las tecnologías, y en el campo profesional y técnico. El ingreso de estudiantes a la educación superior tiene como requisito mínimo la licencia de educación media. La enseńanza de educación superior comprende diferentes niveles de programas formativos, a través de los cuales es posible obtener títulos de técnico de nivel superior, títulos profesionales, grados académicos o títulos universitarios o sus equivalentes".

35 Así lo dispone el artículo 33 de la LOCE, no derogada en esta parte por la LEGE.

36 Es un contrato innominado, con una naturaleza jurídica y una identidad propias, que lo distinguen del arrendamiento de servicios y del mandato, tipos con que frecuentemente lo ha identificado la doctrina. Ver Rosso Elorriaga, Gian Franco (2008) "El Contrato de Educación Superior". En Guzmán Brito, Alejandro (editor científico): "Colección de Estudios de Derecho civil en homenaje a la profesora Inés Pardo de Carvallo". Ediciones Universitarias de Valparaíso, pp. 529 y ss.

37 Nuestra Corte Suprema, conociendo de un recurso de protección, ha declarado que “... se considera que el alumno, al celebrar el respectivo contrato de prestación de servicios educacionales mediante la correspondiente matrícula...”. Corte Suprema, 13 de agosto de 1998, Rol No 2673-98, "Barraza con Colegio Salesiano San Ramón de La Serena", LexisNexis, Jurisprudencia on line, No 15449. En una sentencia reciente, nuestro máximo tribunal revocó un fallo de la I. Corte de Apelaciones de Antofagasta, que no hizo lugar a un recurso de protección planteado por una alumna contra una universidad, que se negaba a concederle el beneficio de continuidad de estudio por haber fallecido su padre y fiador. En el fallo se plantea que los alumnos de ese establecimiento suscriben un contrato de prestación de servicios educacionales y lo hacen al matricularse en esa universidad; y ańade que la universidad "al proceder en la forma descrita en los motivos precedentes aparece negando sin justificación razonable y por mero capricho el beneficio de continuidad de estudios impetrado por la recurrente, siendo, por lo tanto, su actuar arbitrario y vulneratorio de la garantía prevista en el numeral 24 del artículo 19 de la Constitución Política de la República, puesto que con la negativa a otorgar dicha prestación obliga a la alumna a desembolsar sus propios recursos si desea continuar con su carrera. Corte Suprema, 28 de enero de 2014, Rol No 15001-2013. "Sandoval Muńoz Madeleine con Universidad Tecnológica de Chile Inacap”. Thomson Reuters. Cita online: CL/JUR/148/2014; 67377. Rosso (2008) 547 y 548. 


\section{NOCIÓN, TITULARIDAD, REQUISITOS Y FORMA DE EJERCICIO}

\section{1) Noción}

Una interpretación armónica de los dos primeros incisos del Art. $3^{\circ}$ ter nos conduce a la conclusión de que el retracto que establece la LPC designa la facultad unilateral de dejar sin efecto la convención celebrada entre el usuario de un servicio educacional y la institución que lo otorga, sin que concurra alguna otra causal de ineficacia ${ }^{39}$. Junto a los otros modos de retractación que admite la LPC, se inserta en nuestro ordenamiento como una excepción al principio general de la fuerza obligatoria de los contratos. En este caso, la LPC modera el efecto de dejar sin efecto el contrato, porque alcanza solo a servicios que no se han prestado y a una parte del precio pagado.

La expresión retracto admite aquí dos significados, por una parte, es un derecho el de dejar sin efecto el contrato, que comprende varias facultades conexas, la de dejar sin efecto los mandatos otorgados por el alumno, la de recuperar parte de lo pagado, y la de exigir la devolución de los documentos dados en garantía. En otra acepción, designa al acto jurídico por el cual se ejerce ese derecho ${ }^{40}$. En suma, podemos definir el retracto educacional como la facultad del alumno de primer año de una carrera o programa de pregrado ofrecido por una universidad, un instituto profesional o un centro de formación técnica, para que él mismo o quien ha pagado la matrícula en su representación, deje sin efecto el contrato de prestación de servicios educacionales, con solo acreditar, dentro del plazo establecido por la ley, que se encuentra matriculado en otra entidad de educación superior ${ }^{41}$.

39 En Espańa, el Art. 68 del texto refundido de la Ley General para la Defensa de los Consumidores y Usuarios y otras leyes complementarias definió el derecho de desistimiento de un contrato como "la facultad del consumidor y usuario de dejar sin efecto el contrato celebrado, notificándoselo así a la otra parte contratante en el plazo establecido para el ejercicio de ese derecho, sin necesidad de justificar su decisión y sin penalización de ninguna clase".

40 Caprile define genéricamente el desistimiento unilateral como "una forma de extinción del contrato que consiste en la facultad concedida por la ley o por la convención a una o ambas partes para romper unilateralmente el contrato, por su sola voluntad, sin necesidad de un incumplimiento de la contraria, bastando su ejercicio de buena fe y noticiarla con un preaviso razonable a la contraria, so pena de indemnizar los perjuicios en caso de ejercicio irregular". Caprile Biermann, Bruno (2010) "El desistimiento unilateral o renuncia: una especial forma de extinción de los contratos”. Estudios de Derecho Civil IV. Santiago: LegalPublishing, pp. 271296, p. 271.

41 Prado (2003) 163. 


\section{2) TITULARIDAD O LEGITIMACIÓN ACTIVA}

\section{(2.1.) El ALUMNO}

El inciso primero del Art. 3o ter señala que "se faculta al alumno" para dejar sin efecto un contrato de prestación de servicios educacionales de nivel superior, que haya celebrado con alguna de las entidades que menciona -centros de formación técnica, institutos profesionales o universidades-. Según el sentido natural y obvio de la palabra, debe entenderse como alumno al "discípulo de la escuela, colegio o universidad donde estudia”, como reza la definición del Diccionario de la Real Academia de la Lengua Española. En este caso, debe tratarse de quien se ha incorporado como discípulo o estudiante a una universidad, instituto profesional o centro de formación técnica. Obviamente, debe ser una persona natural.

El inciso $2^{\circ}$ del Art. 3 ter, precisa que debe ser alumno de primer año de una carrera o de un programa de pregrado. Debe entenderse que la ley considera que el alumno es parte o al menos beneficiario de un contrato de prestación de servicios educacionales. Será beneficiario cuando tenga esa calidad respecto de un contrato en favor de tercero que haya celebrado alguno de sus padres u otro pariente, lo que es válido y eficaz conforme con el Art. 1449 del Código Civil. El alumno podrá actuar personalmente o a través de mandatario. Si es menor de edad, podrá actuar a través de su representante legal (normalmente el padre o madre que ejerce la patria potestad).

\section{(2.2.) EL “REPRESENTANTE” DEL ALUMNO}

El inciso primero del Art. 3 ter otorga también la facultad de retracto a un segundo titular, al que solo identifica como "quien efectúe el pago en su [del alumno] representación”. No aclara la ley qué es lo que debe haber pagado en representación del alumno. De lo dispuesto en el inciso final de la norma parece desprenderse que se refiere a la cantidad de dinero inicial que se paga en el acto de la matrícula, suma que también se acostumbra a denominar "matrícula".

La letra de la norma admite tres interpretaciones con respecto a quien puede ser el representante habilitado para ejercer el retracto. La primera consiste en que puede ser cualquier persona que haya pagado la matrícula por el alumno. La ley, al hablar de representación no lo habrá hecho en un sentido técnico sino de un modo coloquial, como el que obra a nombre de otro, aunque careza de facultades para representarlo, ya sea legal o voluntariamente. Observemos, en apoyo a esta línea interpretativa, que la disposición parece razonar sobre la base de que aquel retrayente es la misma persona que celebró el contrato que termina a causa 
del retracto, admite incluso la posibilidad de que no haya sido parte en ese contrato, desde el momento en que faculta "a quien efectúe el pago en su representación" para que "deje sin efecto el contrato"; y no impone el requisito de haber sido representante del alumno en la celebración del contrato, sino en el pago del precio de una parte del servicio educacional, es decir, en la ejecución de una de las prestaciones del contrato. Se trata de una situación excepcionalísima en nuestro derecho, en que un sujeto que no ha sido parte del contrato puede dejarlo sin efecto.

Una segunda posición sería que la ley ha usado la expresión "representación" en su sentido técnico, de acuerdo con lo señalado en el Art. 1448 del Código Civil. Entonces, suponiendo que estamos frente a un alumno que es mayor de edad y capaz de administrar sus bienes, debería tratarse de alguien que tenga la representación voluntaria, sea por un contrato de mandato celebrado entre el alumno y su representante o, para un sector de la doctrina, por un acto unilateral de apoderamiento.

Con todo, la norma que analizamos admite una tercera interpretación, según la cual los representantes en el pago a que alude esta disposición solo pueden ser el padre o la madre, o algún otro pariente cercano (abuelo, tío, hermano) del alumno, esto, a pesar de que no menciona, como condición para esta titularidad del retracto, una relación filial o parental entre el alumno y su representante. Nos parece que es posible sostener esta afirmación, aun reconociendo que el tenor literal de este artículo no excluye otro tipo de representante. Esta interpretación se funda precisamente en el régimen institucional en el que se enmarca nuestro sistema de contratación de servicios de educación superior, que expusimos más arriba, y en el que se acostumbra a que un adulto responsable paga la matrícula y asegura el pago del arancel para posibilitar que el alumno quede incorporado en la institución educacional. Es pertinente para este análisis observar que estas normas se enmarcan en un régimen constitucional, según el cual los padres "tienen el derecho de escoger el establecimiento de enseńanza para sus hijos" (Art. 19 No $10 \mathrm{CPR})^{42}$, lo cual sugiere que en la celebración del contrato educacional y en su eventual retractación, se ha previsto con toda probabilidad la intervención del padre o de la madre del alumno, o de ambos. Esta perspectiva parece coherente con el sistema de responsabilidades que rige en Chile en materia de familia ${ }^{43}$.

42 El Art. $4^{\circ}$ de la LEGE es consistente con esta regla constitucional, puesto que dispone que "Corresponde, preferentemente, a los padres de familia el derecho y el deber de educar a sus hijos; al Estado, el deber de otorgar especial protección al ejercicio de este derecho; y, en general, a la comunidad, el deber de contribuir al desarrollo y perfeccionamiento de la educación".

43 Obsérvese, por ejemplo, que nuestro Código Civil define que la posesión notoria de la calidad de hijo respecto de determinada persona, consiste, entre otras cosas, en que "su padre, madre o ambos le hayan tratado como hijo, proveyendo a su educación y establecimiento de un modo competente..." (Art. 200). El Art. 224 dispone que "Toca de consuno a los padres, o al padre o madre sobreviviente, el cuidado personal de la crianza y educación de sus hijos". Esos gastos de crianza y educación de los hijos son de cargo de la 
En todo caso, el establecimiento al que se haga valer el retracto no podría controvertir la legitimación del representante, si consta en sus registros que ha pagado la matrícula en favor del alumno. Asimismo, la institución queda libre de responsabilidad si el representante ejerce el retracto, aunque no se acredite que obra con el consentimiento del alumno; sin embargo, nos parece que no sería válida la retractación del representante contra la voluntad del alumno, pues no basta la intención del que pagó una de las matrículas de recuperar su dinero, para obligar al alumno a consentir en el retracto. La retractación del representante siempre debe ser en el interés del alumno. Con todo, la institución presume que obra en interés del representado. Si no fuera así, el alumno podría demandarlo por el perjuicio que le cause el retracto.

\section{(2.3.) ¿ES EL RETRAYENTE UN CONSUMIDOR O UN USUARIO?}

La introducción de este derecho en una ley cuyo objeto son las relaciones de consumo, y su ubicación en el párrafo $1^{\circ}$ del Título II, bajo el título "los derechos y deberes del consumidor", plantea el problema de considerar los elementos que deben concurrir para que un contrato sea una relación de consumo, porque sin ella no cabe hablar de consumidores ni de proveedores. En la LPC, la existencia de esos sujetos se deriva y depende de una relación de consumo.

El Art. $1^{\circ}$ No 1 de la LPC comprende, en un mismo concepto, a los "Consumidores" y a los "Usuarios", y define que, para los efectos de esta ley, lo serán las personas que, por un acto jurídico oneroso, adquieran, utilicen, o disfruten, como destinatarios finales, bienes o servicios y que no puedan ser considerados como proveedores. En su texto original de 1997, este artículo aplicaba ese concepto solo a "los consumidores"; el término "usuarios" fue introducido en 2004 por la Ley No 19.955, siguiendo la tendencia observada en algunas legislaciones extranjeras. La expresión "usuarios" parece más adecuada para los sujetos que contratan servicios, por lo que, en rigor, deberíamos aplicarla al referirnos a las personas en cuyo beneficio se estableció el artículo $3^{\circ}$ ter, y reservar la expresión "consumidor" a las relaciones contractuales que recaen sobre bienes que no son servicios.

El artículo $1^{\circ}$ de la LPC dispone que, para los efectos de esa ley, se entenderá por consumidores o usuarios "las personas naturales o jurídicas

sociedad conyugal, si la hay; en caso contrario, los padres deben contribuir en proporción a sus respectivas facultades económicas (Arts. 230 y 1740 No5). El Art. 236 establece que los padres "tendrán el derecho y el deber de educar a sus hijos, orientándolos hacia su pleno desarrollo en las distintas etapas de su vida". Incluso, si el hijo abandonado por sus padres hubiere sido alimentado y criado por otra persona, y quisieren sus padres sacarle del poder de ella, entre otras condiciones, "deberán pagarle los costos de su crianza y educación, tasados por el juez" (Art. 240). 
que, en virtud de cualquier acto jurídico oneroso, adquieren, utilizan, o disfrutan, como destinatarios finales, bienes o servicios". Si nos detenemos a observar el caso del alumno retrayente, la definición citada pone en jaque la concurrencia de la onerosidad en los casos en que un tercero paga el precio del contrato educacional. Una suerte parecida corre el representante del alumno que ejerce un retracto respecto de un servicio del cual no ha sido destinatario. Resulta evidente, entonces, la importancia de precisar el significado de los términos acto jurídico oneroso y destinatario final, para aplicar la LPC al contrato de educación superior ${ }^{44}$ : es por la fuerza de ambos elementos que la contraparte del proveedor adquiere la calidad de consumidor para los efectos de la LPC.

Con respecto al primero de estos elementos, sucede que existen, en la realidad, un "consumidor jurídico", que es la persona que contrata al proveedor y le paga, y un "consumidor material" que no necesariamente coincide con el anterior ${ }^{45}$, que es la persona que, gracias a un contrato existente, utiliza o disfruta el bien o el servicio, como su destinatario final, y que puede alcanzar ese uso o disfrute sin haber contratado él mismo con el proveedor, y sin haber incurrido en un sacrificio en dinero o evaluable en dinero ${ }^{46}$. En cuanto a la expresión destinatario final, con la

44 Para entender la expresión "acto jurídico oneroso" que emplea la definición de consumidor contenida en el Art. $1^{\circ}$ de la LPC, habría que asimilar esta expresión al concepto de contrato oneroso, que se contrapone a la idea de contrato gratuito. El Art. 1440 del Código Civil dice que el contrato es gratuito o de beneficencia cuando solo tiene por objeto la utilidad de una de las partes, sufriendo la otra el gravamen; y oneroso, cuando tiene por objeto la utilidad de ambos contratantes, gravándose cada uno a beneficio del otro. Alessandri explica que para hacer la clasificación entre contratos onerosos y gratuitos, "se atiende a la utilidad que el contrato reporta a las partes. Si ambas la obtienen, es oneroso, porque en tal caso ambas deben soportar un gravamen; de otro modo no habría beneficio recíproco. Por eso se llama oneroso; cada contratante no reporta utilidad del contrato sino mediante un sacrificio. Si solo una de las partes la obtiene, el contrato es gratuito o de beneficencia; para obtener la utilidad que recibió, no le ha sido menester ningún sacrificio. El gravamen lo soporta el otro contratante únicamente”. Alessandri Rodríguez, Arturo (2004) De Los Contratos. Editorial Jurídica de Chile. p. 22.

45 La Consecuencia práctica de esta distinción entre consumidor jurídico y consumidor material, es que si ambas condiciones no coinciden en una misma persona, el consumidor meramente material no podría ejercer los derechos que la ley otorga al consumidor jurídico. Ver Bercovitz Rodríguez-Cano, Alberto y Bercovitz Rodríguez-Cano, Rodrigo (1987) Estudios Jurídicos sobre Protección a los Consumidores. Madrid: Tecnos, 326 pp., p. 133. En nuestro país, Momberg considera que la interpretación adecuada de la norma del Art. $1^{\circ} \mathrm{N}^{\circ} 1$ de la LPC, tomando en cuenta la finalidad de protección de la ley hacia el consumidor, "debiera incluir tanto al consumidor jurídico como al consumidor material". La jurisprudencia de nuestros tribunales no ha seguido un uniforme en esta materia. Ver Momberg Uribe, Rodrigo (2013) “Artículo 10 No 1". En De la Maza Gazmuri, Ińigo y Pizarro Wilson, Carlos (directores) y Barrientos Camus, Francisca (coordinadora): La Protección de los Derechos de los Consumidores. Santiago: Thomson Reuters, pp. 7-8.

46 Este requisito no aparece en el mensaje ni estaba en el proyecto de ley enviado al Congreso, simplemente aparece durante la tramitación de ese proyecto en la Comisión de Economía del Senado y no hay registro en las actas de esa comisión ni en las discusiones parlamentarias sobre los motivos para introducir esta condición en la relación jurídica que da origen a un acto de consumo regido por la LPC. Ver Primer Informe de la Comisión 
cual nuestra LPC restringe también la noción de consumidor ${ }^{47}$, hemos de decir que ella es común en la legislación comparada ${ }^{48}$, y que, en la LPC, no está tomada en una acepción jurídica, sino en un sentido económico, para designar al sujeto que agota el proceso de circulación de los bienes y no vuelve a incorporarlo al círculo de la economía ${ }^{49}$. En un sentido estrictamente jurídico, al menos en el derecho privado, el "destinatario" corresponde a la persona que recibe una oferta ${ }^{50}$ para celebrar un contrato; aquí, en cambio, se considera como destinatario a quien va hacer uso del bien o servicio. También hemos de considerar que, en derecho del consumidor -como explica Schvartz-, existen dos vertientes: una $f i$ nalista, que define al consumidor como el sujeto que adquiere el bien o el servicio como destinatario final, "se constituye en el último eslabón de la cadena productiva y lo hace desaparecer del mercado, ello sin perjuicio de que se trate de una persona física o jurídica. Excluye, en consecuencia, toda transacción en virtud de la cual el bien o servicio adquirido se integre nuevamente a la cadena productiva o sea comercializando" 51 . Por el contrario la tesis maximalista interpreta el concepto de destinatario final en forma literal, "de modo tal, que considera incluido en su plexo tuitivo todas las situaciones, aun aquellas en las cuales el adquirente haya destinado el producto o servicio para integrarlo a su vez a la cadena de

de Economía del Senado, Sesión 45a especial, Legislatura Extraordinaria, 15 marzo 1995, Diario de Sesiones del Senado (anexo de documentos), p. 4879.

47 Esta disposición está tomada de la LGCU española, particularmente de la norma que definía a los consumidores y usuarios (artículo 1.2) como "las personas físicas o jurídicas que adquieren, utilizan o disfrutan como destinatarios finales, bienes muebles o inmuebles, productos, servicios, actividades of funciones, cualquiera que sea la naturaleza pública o privada, individual o colectiva de quienes los producen, facilitan, suministran o expiden". La norma de nuestra LPC es casi idéntica y la única diferencia importante es, precisamente, el título o causa de la adquisición: "en virtud de cualquier acto jurídico oneroso" que no puede explicarse, a nuestro juicio, sino en la voluntad de restringir o precisar la aplicación del concepto de consumidor. Ver Primer Informe de la Comisión de Economía del Senado, Sesión 45a especial, Legislatura Extraordinaria, 15 marzo 1995, Diario de Sesiones del Senado (anexo de documentos), p. 4.879.

48 En Brasil, por ejemplo, el Código de Defensa del Consumidor, de 1990 -Lei 8.078-, otorga su protección al consumidor final, que puede ser una persona física o jurídica. Ver Maldonado De Carvalho, José Carlos (2007) Direito do Consumidor. Fundamentos Doutrinários e Visão Jurisprudencial. Sao Paulo: Lumen Juris Editora, 553 pp.

49 "Si los bienes o servicios - dice Sandoval-, se obtienen mediante un acto jurídico a título gratuito (donación o comodato) o se adquieren o se requieren como intermediario para ser colocados o prestados a otros operadores de la actividad económica, no estamos en presencia de un consumidor”. Sandoval López (2004) 39. Ver Botana García, Gema Alejandra (2001) Comercio Electrónico y Protección de los Consumidores. Madrid: Editorial La Ley, p. 209.

"La oferta, llamada también propuesta o policitación, es el acto por el cual una persona propone a otra la celebración de un contrato sobre bases determinadas". Alessandri Rodríguez (2004) 88.

51 A esta concepción se adscriben las leyes argentina y brasileña. 
producción" 52 . Esta concepción del destinatario final es común en la doctrina extranjera y en la legislación comparada ${ }^{53}$.

Sin embargo, también es patente la tendencia a liberar a algunos sujetos de esta limitación del ámbito de aplicación del derecho del consumidor, por ser evidentes las injusticias que se cometen obligando al juez a aplicarla ${ }^{54}$.

A la vista de los requisitos que esta ley impone para ser usuario o consumidor, cabe preguntarse, entonces, si estos servicios corresponden o no a las relaciones de consumo que ella regula porque, de acuerdo con su artículo $2^{\circ}$ letra a), sus normas se aplican, con carácter general, a los actos jurídicos que tengan el carácter de mercantiles para el proveedor y de civiles para el consumidor, es decir, aquellos que en doctrina se conocen como actos mixtos o de doble carácter ${ }^{5}$. Sucede que, en nuestro país, los contratos educacionales siempre son civiles, porque no han sido tipificados como mercantiles. Por eso, la LPC dispone que los contratos de edu-

52 Schvartz, Liliana Beatriz (2003) Los Informes Comerciales. Régimen Jurídico en Argentina Perú - México - Brasil - Chile - Paraguay - Colombia. Buenos Aires: Lumiere, p. 37.

53 En la opinión de Cabañas, lo que primordialmente caracteriza al consumidor y usuario, "es su condición de destinatario final del producto o servicio, en cuanto lo emplea a la satisfacción de sus propias necesidades personales familiares, o eventualmente para entregar a un tercero pero nunca para la obtención de un rendimiento económico, entendido como actividad productiva. La doctrina exige que el bien o servicio no se adquiera o transmita para su introducción en el mercado". Ver Cabañas García, Juan Carlos (2005) Los procesos civiles sobre consumidores y usuarios y de control de las cláusulas generales de los contratos. Madrid: Tecnos, pp. 166 y ss.

La LGCU española contenía una definición muy similar a la del artículo $1^{\circ}$ de nuestra LPC, puesto que, en su artículo 1.2 considera consumidores o usuarios a "las personas físicas o jurídicas que adquieren, utilizan o disfrutan, "como destinatarios finales", bienes muebles o inmuebles, productos, servicios, actividades o funciones, cualquiera que sea la naturaleza pública o privada, individual o colectiva, de quienes los producen, facilitan, suministran o expiden" y, después de definir así a los consumidores y usuarios establece en su apartado 3 que "No tendrán la consideración de consumidores o usuarios quienes sin constituirse en destinatarios finales, adquieran, almacenen, utilicen o consuman bienes o servicios, con el fin de integrarlos en procesos de producción, transformación, comercialización o prestación a terceros". Asimismo, el Art. IV del Código de Protección y Defensa del Consumidor peruano dispone que "No se considera consumidor para efectos de este Código a quien adquiere, utiliza o disfruta de un producto o servicio normalmente destinado para los fines de su actividad como proveedor". El Art. $2^{\circ}$ de la Ley de Defensa del Consumidor uruguaya, establece que "No se considera consumidor o usuario a aquel que, sin constituirse en destinatario final, adquiere, almacena, utiliza o consume productos o servicios con el fin de integrarlos en procesos y en que, en su Art. 2 establece que "No se considera consumidor o usuario a aquel que, sin constituirse en destinatario final, adquiere, almacena, utiliza o consume productos o servicios con el fin de integrarlos en procesos de producción, transformación o comercialización".

54 En el derecho comparado, al sujeto que sufre un daño, no por realizar el acto de consumo mismo (adquirir, utilizar o disfrutar como destinatario final) sino por su proximidad al producto, se le denomina by-stander y, también, tercero ajeno al consumo o consumidor potencial. Ver López Santa María, Jorge (2002) "Responsabilidad Civil por Productos". En Derecho de Daños. Santiago: LexisNexis, pp. 153 y ss.

55 Puga Vial, Juan Esteban (2005) El Acto de Comercio. Crítica a la Doctrina Tradicional. Santiago: Editorial Jurídica de Chile, 266 pp., pp 17 y ss. 
cación -de enseñanza básica, media, técnico profesional o universitariase sujetan a sus disposiciones, de acuerdo con su artículo $2^{\circ}$ letra d), "solo respecto" del Párrafo $4^{\circ}$ del Título II; de los Párrafos $1^{\circ}$ y $2^{\circ}$ del Título III; de los artículos 18, 24, 26, 27 y 39 C, y respecto de las acciones judiciales que establece "para hacer efectivos los derechos que dichos párrafos y artículos les confieren" 56 . Curiosamente, dentro del carácter excepcional de las normas aplicables que cita el Art. $2^{\circ}$ letra d) no se comprende el retracto de los contratos de educación superior, porque el Art. $3^{\circ}$ ter se ubica en el párrafo $1^{\circ}$ del Título II. Pensamos, sin embargo, que esto se ha debido a una inadvertencia del legislador y que resulta manifiesto que la intención ha sido que el alumno, o quien lo haya representado en el pago, para efectos del retracto debe ser considerado también consumidor, o más correctamente, usuario.

El retrayente del contrato de educación superior es un tipo muy especial de consumidor, porque, en general, los estudios superiores que un alumno cursa en un establecimiento educacional no dan lugar a una relación de consumo; lo es para los efectos de ejercer este derecho de desistimiento unilateral, por tal razón, la LPC ha ubicado ese derecho en un párrafo que se denomina precisamente "los derechos y deberes del consumidor". De esta forma, la institución que estudiamos opera como un dispositivo que morigera algunos efectos negativos de ese mecanismo de selección, para los alumnos que ingresan a la educación superior y para sus familias, y tiene por objeto garantizar la libertad de los estudiantes de pregrado, de elegir entre los establecimientos que ofrecen la carrera que les interesa seguir, y la eficacia de los derechos con que se protege la familia en nuestro país.

\section{3) REQUisitos}

\section{(3.1.) SOLICITUD EXPRESA ANTE LA RESPECTIVA INSTITUCIÓN}

El inciso primero del artículo $3^{\circ}$ ter comienza diciendo: "En el caso de prestaciones de servicios educacionales de nivel superior, proporcionadas por centros de formación técnica, institutos profesionales y universidades, se faculta..."; y alude al afectado por el retracto como "la respectiva institución". El inciso siguiente regula el ejercicio y los efectos de este derecho, y establece que para hacerlo efectivo se requiere ser alumno de primer año de una carrera o programa de pregrado y acreditar, "ante la

56 Esto último, con la salvedad de que no queda sujeto a la LPC el derecho a recurrir judicialmente por la calidad de la educación o por las condiciones académicas fijadas en los reglamentos internos vigentes a la época del ingreso a la carrera o programa respectivo, "los cuales no podrán ser alterados sustancialmente, en forma arbitraria, sin perjuicio de las obligaciones de dar fiel cumplimiento a los términos, condiciones y modalidades ofrecidas por las entidades de educación" (Art. 20, letra d). 
institución respecto de la cual se ejerce esta facultad", una matrícula vigente en otra entidad de educación superior, de donde se sigue que no es posible invocar este retracto ante los establecimientos de enseńanza que la legislación chilena no considera de educación superior ${ }^{57}$.

Parece claro que cuando la ley se refiere en forma general a "la respectiva institución" o a la "institución educacional" está indicando al establecimiento con el cual se celebró el contrato de prestación de servicios de educación superior y que, según el inciso primero del Art. 3 ter, puede ser o un centro de formación técnica, o un instituto profesional o una universidad. Si el alumno se ha incorporado a otra institución de educación superior (una escuela superior ligada a las Fuerzas Armadas, por ejemplo), carecerá del derecho de retracto. Debe considerarse que, siendo una norma de excepción, ha de interpretarse restrictivamente.

\section{(3.2.) ACREDitación de SEgUNda MATRÍCULA}

El inciso segundo del Art. 3 ter señala que para ejercer el derecho de retracto, el titular debe "acreditar, ante la institución respecto de la cual se ejerce esta facultad, encontrarse matriculado en otra entidad de educación superior".

Luego, el ejercicio del retracto del contrato de educación superior está supeditado a que el alumno se haya incorporado, mediante la correspondiente matrícula, en otra entidad de educación superior. Nótese que aquí la ley no señala que deba tratarse de un centro de formación técnica, instituto profesional o universidad, de modo que caben las otras instituciones de educación superior que no tienen este carácter. La norma exige que esta matrícula se "acredite" ante la institución cuyo contrato se está dejando si efecto. Entendemos que bastará un certificado o copia del documento en que conste la matrícula en la otra institución para que se dé por acreditado, sin que la institución objeto del retracto pueda exigir una prueba de mayor entidad.

¿Debe la matrícula que se invoca para ejercer el retracto ser posterior al contrato que se pretende dejar sin efecto por el ejercicio de esta facultad? Esto es lo que sucederá más frecuentemente, por la forma en que se plantea el problema que se pretendió solucionar con la norma; pero esto no fue exigido, por lo que incluso si la matrícula invocada fuera anterior a aquella que se pretende retraer, el retracto es procedente: el titular podrá acreditar que "se encuentra" matriculado en otra entidad de educación superior.

\footnotetext{
57 Según las categorías del Art. 17 de la LEGE, corresponden a enseñanza parvularia, básica y media o por modalidades educativas dirigidas a atender a poblaciones específicas.
} 


\section{(3.3.) EJERCICIO DENTRO DEL PLAZO LEGAL}

La exigencia de un plazo para ejercer el derecho es un requisito común a las diversas formas de desistimiento contractual.

En el retracto educacional es un término de diez días que, y se cuenta desde la medianoche del día siguiente a aquel en que se complete la primera publicación de los resultados de las postulaciones a las universidades pertenecientes al Consejo de Rectores. La ley no menciona una determinada forma de publicación, por lo que debemos entender que basta cualquier forma idónea y fidedigna de dar a conocer esos resultados, incluyendo internet, que es la usada en los últimos años. Se trata de un plazo fatal (se usa la expresión "dentro de" que es indicativa de este tipo de plazos $^{58}$ ) y de días corridos (se cuentan los feriados o festivos). Sobre estas características del plazo se ha pronunciado la Corte Suprema ${ }^{59}$. Pensamos que un plazo tan breve debe ser estimado como de caducidad, porque no estamos frente a un periodo tan extenso, como para sostener que por la "dentro del plazo de diez días..." ejerza el retracto. Según la regla general del Art. 49 del Código Civil, cuando se dice que un acto debe ejecutarse dentro de cierto plazo, se entenderá que vale si se ejecuta antes de la medianoche en que termina el último día del plazo.

59 Se trata de un recurso de protección interpuesto por una alumna universitaria, que formuló su retracto al día undécimo de que este empezara a correr; la institución universitaria, después de recibir el retracto extemporáneo de la alumna matriculada en la carrera de medicina, le ofreció una condonación parcial, consistente en dejar sin efecto el $80 \%$ del cobro del arancel anual, y fijó como condición para ello el pago previo del valor de la matrícula y del $20 \%$ del arancel restante. El fallo establece que el plazo del Art. $3^{\circ}$ ter es fatal y de días corridos, conforme lo disponen los artículos 49 y 50 del CC. No obstante, la misma sentencia, por mayoría, se pronuncia a favor de acoger el recurso de protección. Las razones que tuvo en cuenta la Corte para fallar a favor de la recurrente fueron que, al estar vencido el plazo de retracto, era legítima la decisión de rechazarlo; sin embargo, si la universidad estaba de acuerdo en dejar sin efecto el convenio de educación que ligaba a las partes bajo otras condiciones, entonces el cobro del $20 \%$ del arancel anual de la carrera de Medicina, más el pago de la matrícula, constituyó un acto arbitrario, porque, de haber retracto, la LPC "faculta a la universidad respectiva a retener por concepto de costos de administración hasta el $1 \%$ del arancel anual de la respectiva carrera, con lo que, en el caso de autos, el retracto presentado con un día de desfase en relación al plazo fatal indicado que cobra un $20 \%$ del arancel anual resulta arbitrario. En efecto, se está en la hipótesis que al iniciar la universidad el proceso definitivo de planificación de actividades la recurrente dio cuenta de su decisión de no perseverar en sus estudios, por lo cual no se ha producido un daño superior al normal a cualquier retracto temporario. Es esta circunstancia, unida a la voluntad de la universidad de no perseverar en el contrato educacional, la cual denotó un exceso en las exigencias pecuniarias lo que afecta la garantía prevista en el artículo $19 \mathrm{~N}^{\circ} 24$ de la Carta Política, por cuanto hace soportar a la recurrente un costo mayor al que razonablemente ha debido soportar la universidad, el que se entiende proporcional a un porcentaje igual al fijado por el legislador por 10 días, esto es al $1 \%$ del arancel anual, conforme a lo cual la alumna deberá pagar ambas cantidades, las que suman un $2 \%$ del arancel anual, más la matrícula respectiva" Corte Suprema, 10 de octubre de 2013, Rol No 4512-2013 "Valdivieso, María de los Ángeles con Universidad San Sebastián”. Thomson Reuters. Cita online: CL/ JUR/2167/2013). 
inactividad del titular del derecho la ley presume su desinterés en él y su voluntad de renunciarlo; más bien, vemos un derecho de vida limitada, algo que caracteriza precisamente a la caducidad y que permite distinguirla de otros fenómenos, como la prescripción y la preclusión ${ }^{60}$. Por tratarse de una caducidad, no se necesita alegación de parte y puede ser declarada de oficio por el juez. Tampoco se suspende en favor de personas incapaces ni se interrumpe.

\section{4) Forma DE EJERCICIO}

El retracto se ejerce expresando, a través de cualquier medio fehaciente, la voluntad del retrayente de dejar sin efecto el contrato de educación superior, ante la institución educacional con que se ha contratado. Se hace necesario que la voluntad de retractarse sea comunicada a la institución educacional ${ }^{61}$.

El ejercicio ordinario es extrajudicial, porque, cumplidos los requisitos, este derecho nace por el solo ministerio de la ley y la entidad educacional no puede oponerse legítimamente a su ejercicio. Solo cuando la institución se oponga al retracto, este deberá ser demandado judicialmente. Como los titulares del derecho son considerados consumidores (en rigor, usuarios) para estos efectos, podrán acudir a los tribunales que establece la LPC, para ejercer los derechos de los consumidores, y demandar judicialmente que su retracto sea reconocido en su validez o en sus efectos. Se aplicará el Art. 50 LPC según el cual las acciones judiciales que derivan de esta ley pueden ejercerse si se afecta "el ejercicio de cualquiera de los derechos" de los consumidores. Este artículo contiene un inciso segundo que ofrece varias formas de amparar los derechos de los consumidores: dice que "el incumplimiento de las normas contenidas en la presente ley dará lugar a las acciones destinadas a sancionar al proveedor que incurra en infracción, anular las cláusulas abusivas incorporadas en los contratos de adhesión, obtener la prestación de la obligación incumplida, hacer cesar el acto que afecte el ejercicio de los derechos de los consumi-

60 Nuestra Corte Suprema ha declarado que "la caducidad es la pérdida de la facultad de hacer valer un derecho como consecuencia de la expiración de un plazo fatal". Corte Suprema, 28 de enero de 1988, en Fallos del Mes 350, No 2, p 1021. Domínguez Águila, Ramón (2009) La Prescripción Extintiva. Doctrina y Jurisprudencia. Santiago: Editorial Jurídica de Chile. 435 pp, p. 125 y ss.

61 Caprile distingue entre el ejercicio regular del retracto, que se produce siempre que el proveedor haya tomado conocimiento del ejercicio de esta facultad, de su ejercicio irregular, que ocurre si el proveedor no ha sido notificado, y estima que este desistimiento resulta inoponible a la contraparte del contrato que se busca dejar sin efecto. CapriLe BiermanN (2010) 95. Bermúdez, siguiendo la regulación que sobre este punto ha seguido el derecho comunitario europeo, se inclina por la teoría de la expedición, de tal forma que bastaría el envío de la comunicación que contiene la decisión del retrayente para que el retracto produzca plenos efectos. Bermúdez (2001) 96. 
dores, a obtener la debida indemnización de perjuicios o la reparación que corresponda”.

De esta manera, ante la negativa injustificada del establecimiento educacional a admitir el retracto, el titular de este derecho podrá pedir que se declare la ineficacia del contrato, que se le restituyan los valores o documentos que hayan sido entregados en virtud del contrato que ha sido objeto del retracto, que se sancione a la institución incumplidora y que se le indemnicen los perjuicios causados.

En este proceso, el demandante deberá probar que ejerció oportunamente el derecho de retracto. También se deberá probar que se celebró el contrato que se pretende dejar sin efecto con el retracto. En general, los contratos que se perfeccionan con el solo consentimiento de las partes presentan una severa dificultad probatoria, puesto que en nuestro ordenamiento jurídico no se admite la prueba de testigos de un contrato que contenga una obligación o promesa de ella que valga más de dos unidades tributarias ${ }^{62}$. No obstante, aunque no se haya celebrado un contrato escrito con el establecimiento educacional, el comprobante de pago del arancel de matrícula es un antecedente documental cuya existencia solo se justifica porque existe ese contrato, y constituye un "principio de prueba por escrito", es decir, un acto escrito del demandado que hace verosímil el hecho litigioso, como lo define el artículo 1711 del Código Civil. Esa misma norma hace admisible, en estos casos, la prueba testimonial aun respecto de obligaciones que valen menos de 2 UTM.

\section{EFECTOS DEL RETRACTO EDUCACIONAL}

\section{1) INEFICACIA CONTRACTUAL}

\section{(1.1.) ¿CUMPLIMIENTO DE UNA CONDICIÓN RESOlUTORIA MERAMENTE POTESTATIVA?}

En general, se afirma que el efecto fundamental del ejercicio de esta facultad es la terminación del contrato de prestación de servicios con la institución de educación superior ${ }^{63}$, y las palabras que emplea la ley parecieran no dejar lugar a dudas de que, antes del retracto, realmente hubo un contrato, ese que se deja sin efecto. El inciso primero del Art. $3^{\circ}$ ter

62 Véanse los artículos 1708, 1709 y 1710 del Código Civil.

63 Brantt/Mejías (2013) 189. También, López Santa María, Jorge (2010) Los Contratos. Parte General. Santiago: Thomson Reuters, 610 pp., pp. 276 y 277. Rosas Zambrano, Marco antonio (2014) "Posibilidad de dejar sin efecto el contrato en la Ley del Consumidor". Cuadernos de Análisis Jurídico, Colección de Derecho Privado VIII. Condiciones Generales de la Contratación y Cláusulas abusivas. Santiago: Ediciones Universidad Diego Portales, pp. 243-258, p. 253. 
LPC, señala que, al manifestar oportunamente su voluntad de retractarse, el retrayente deja "sin efecto el contrato".

Si se considera que el retracto tiene lugar durante la ejecución del contrato, entonces podría concluirse que, mientras este derecho no se ejerza, el contrato existe, pero su eficacia depende de un "acontecimiento futuro, que puede suceder o no" (Art. 1475 CC), a saber, que la retractación se plantee en tiempo y forma. Bajo esta perspectiva, entonces, la retractación vendría a ser el cumplimiento de una condición resolutoria y meramente potestativa ${ }^{64}$, que resuelve el contrato, y que ha sido establecida a favor de una de las partes por expresa disposición de la ley ${ }^{65}$, de tal forma que el contrato termina con el acto en que el retrayente plantea su retractación ${ }^{66}$. Pensamos que no es aplicable aquí el Art. 1478 del Código Civil, conforme al cual "son nulas las obligaciones contraídas bajo una condición potestativa que consista en la mera voluntad de la persona que se obligue", porque este precepto, como lo pone de manifiesto su texto, se aplica solo a las condiciones suspensivas, no a las resolutorias.

También puede sostenerse que es una condición que depende de la voluntad del acreedor, porque tratándose de un contrato conmutativo ambas partes tienen la doble posición de acreedor y deudor ${ }^{67}$. Bien puede señalarse que no hay aquí una propia condición resolutoria, como tampoco lo es la llamada condición resolutoria tácita del Art. 1489 CC, sino solo una forma de ineficacia sobrevenida del acto jurídico que cae en la categoría general del desistimiento ${ }^{68}$.

\section{2. ¿INCUMPLIMIENTO LÍCITO?}

La legitimación legal del término del contrato por la voluntad de una sola de las partes, ha conducido a cierta doctrina a calificarlo una suerte de incumplimiento lícito. En la doctrina francesa, Cécile Chabas,

64 El Art. 1479 del Código Civil chileno dispone que la condición es resolutoria, "cuando por su cumplimiento se extingue un derecho”. El Art. 1477 añade que se llama condición potestativa la que depende de la voluntad del acreedor o del deudor.

65 Es una condición positiva, pues se trata de "acontecer una cosa" (Art. 1474 CC), que, como tal, debe ser "moralmente posible", y que se torna moralmente imposible si, eventualmente, se opone "a las buenas costumbres o al orden público" (Art. 1575 CC).

66 Prado (2013) 163.

67 Así, Momberg opina que el retracto es una condición meramente potestativa que depende de la sola voluntad del consumidor, que siendo aquí acreedor, no sería alcanzada por la sanción del Art. 1478 del Código Civil. Momberg Uribe, Rodrigo (2005) "El derecho de retracto en los contratos de consumo”. En Corral Talciani, Hernán y Rodríguez, María Sara (editores): Estudios de Derecho Civil. Santiago: LexisNexis, p. 305.

68 Pinochet observa que el retracto de la LPC no exige la exige la concurrencia de una causa objetiva que justifique su ejercicio, como sucede con la condición resolutoria. Pinochet Olave, Ruperto (2013) “Artículo 3o bis”. En De la Maza Gazmuri, Ińigo y Pizarro Wilson, Carlos (directores) y Barrientos Camus, Francisca (coordinadora): La Protección de los Derechos de los Consumidores. Santiago: Thomson Reuters, pp. 167-175, p. 173. 
por ejemplo, distingue entre inejecuciones lícitas e ilícitas ${ }^{69}$. En Chile, ha sido sugerido por Pizarro ${ }^{70}$.

No estamos de acuerdo con esta posición, incluso pensando que estamos frente a la terminación de un contrato ya perfecto. En tal supuesto, estaríamos frente al ejercicio de un derecho que la ley misma conferiría al retrayente para dejar sin efecto el contrato, pero si este queda sin efecto, no puede hablarse de obligación contractual incumplida.

\section{(1.3.) NUESTRA OPINIÓN: REQUISITO NECESARIO PARA LA FORMACIÓN DEL CONSENTIMIENTO CONTRACTUAL}

Según otra opinión doctrinal mientras no venza el plazo de retracto y en tanto este no se produzca, no se ha consolidado la relación jurídica entre las partes. El consentimiento no se habría formado en plenitud, pese a la coincidencia entre ellas sobre el servicio contratado y su valor. El plazo de retracto constituiría entonces un elemento adicional al acuerdo de los contratantes, que en este contrato es necesario para que nazca a la vida jurídica con plenos efectos. Siguiendo esta línea de interpretación, mientras no se extinga el plazo de retracto no habría contrato de prestación de servicios educacionales, sino meras estipulaciones preliminares. Solo lo habría si la retractación no es planteada oportunamente y con los requisitos legales ${ }^{71}$.

En abono de esta posición puede decirse que explica mejor por qué el que ha pagado en representación del alumno puede ejercer el retracto, pese a no ser parte del contrato. Observemos que el inciso primero del Art. $3^{\circ}$ ter de la LPC, no habla de dejar sin efecto el contrato celebrado entre el retrayente y el establecimiento educativo, en virtud de la retractación, sino que se refiere "al caso" ["En el caso..."] de las prestaciones de servicios educacionales de nivel superior, y si bien faculta al alumno y a su representante en el pago para dejar "sin efecto el contrato con la respectiva institución", tal facultad puede no referirse necesariamente al contrato ya celebrado, sino al que podría nacer de no mediar el retracto.

Chabas, Cécile (2002) Linexecution licite du contrat. Paris: Bibliotheque de Droit Privé. T. 380, 548 pp.

Pizarro (2005) 235 y ss.

"En la dogmática -explica Carlos Pizarro- coexisten dos concepciones en cuanto a la formación del consentimiento. De una parte, la explicación tradicional, según la cual, el consentimiento se forma de manera instantánea. Basta el encuentro entre la oferta y la aceptación para que se configure el vínculo contractual dando inmediata vigencia al principio de la fuerza obligatoria del contrato. En esta perspectiva el derecho de retracto interviene a la época de ejecución del contrato, colocando término de manera unilateral al acto ya formado. En este contexto el derecho de retracto se asimila al ejercicio de un derecho de resolución unilateral. Sin embargo, para otra doctrina el derecho de retracto no opera en la fase de ejecución del contrato, sino que durante la formación evolutiva del mismo. En este caso se plantea una formación progresiva del consentimiento contractual". Pizarro (2005) 238. 
Nos parece que esta es la solución más adecuada al sentido de la ley y a la forma en que opera esta institución: el retracto no resuelve nada, sino que deja en suspenso la eficacia de la voluntad de los contrayentes para generar un contrato, en este caso el de educación superior. Por eso la privación de efectos de la matrícula, que es la consecuencia jurídica principal que se sigue del ejercicio del retracto, no se produce con carácter resolutorio, sino para el futuro, ordinariamente, antes de que los servicios de enseñanza hayan comenzado. Así también se entiende por qué este mismo artículo, al final de su inciso tercero, dispone que el prestador del servicio educacional debe abstenerse de "negociar o endosar los documentos recibidos, antes del plazo señalado en el inciso primero", lo cual significa que, una vez vencido el plazo seńalado para plantear el retracto, si ninguno de los retrayentes autorizados por la ley ejerce esa facultad, entonces el establecimiento educacional puede ceder los documentos recibidos, con plena libertad; la explicación vendría a ser que, desde ese momento, el contrato nace a la vida jurídica.

Mientras no se extinga el plazo de retractación no hay contrato, el que solo existirá si el retracto no es ejercido oportunamente. Si alguno de los intervinientes en la relación precontractual falta a las obligaciones que la ley en el Art. $3^{\circ}$ ter les ha impuesto, no deberían aplicarse las reglas de la responsabilidad contractual, sino las de la responsabilidad extracontractual ${ }^{72}$. Aunque no esté formado el contrato, el retracto se ejerce a través de un acto jurídico, de modo que se aplicarán las reglas generales en materia de capacidad para ejecutar el acto.

\section{2) PROHIBICIÓN DE RETENER DiNero O DOCUMENTOS DE PAgo O CRÉDITO Y OBLIGACIÓN DE RESTITUIRLOS}

El inciso tercero del Art. $3^{\circ}$ ter prohíbe a la institución educacional retener los dineros pagados o los documentos de pago o crédito otorgados en respaldo del período educacional respectivo, y le ordena devolver esos dineros y esos documentos en el plazo de diez días desde que se ejerza el retracto. La norma no dice a quien se deben entregar esos dineros o esos documentos. Si es el alumno quien pagó o firmó los documentos el que ejerce el retracto, no parece haber problemas: la entrega se le hará al mismo retrayente. Igualmente, no habrá dificultades si quien pagó es un tercero que actuó en representación del alumno y es él quien ejerce el derecho. Pero, ¿qué sucede si ha sido un tercero quien pagó y firmó los documentos y es el alumno el que ejerce el retracto? En esta hipótesis, pensamos que la devolución debe hacerse a la persona que efectuó el

72 Sobre el régimen legal de la responsabilidad "precontractual": Corral Talciani, Hernán (2003) Lecciones de Responsabilidad Extracontractual. Santiago: Editorial Jurídica de Chile, pp. 39-41; Zuloaga Ríos, Isabel Margarita (2006) Teoría de la Responsabilidad Precontractual. Aplicaciones en la formación del consentimiento de los contratos. Santiago: LexisNexis, p. 55. 
pago, porque esa es la regla en materia de restituciones mutuas, y porque si se hace la devolución a un alumno retrayente que no ha hecho pago alguno, se vulneraría el principio general que prohíbe el enriquecimiento sin causa.

\section{3) REVOCACIÓN DE MANDATOS}

El ejercicio del retracto ante la institución educacional produce también la terminación ipso iure del mandato que se haya otorgado, eventualmente, para hacer futuros cobros.

El Art. 3 ter LPC no distingue entre un mandato otorgado al mismo establecimiento o a un tercero, por lo que la terminación se aplicará a ambas clases de mandato. Como apunta Pizarro, la LPC establece aquí una suerte de "indivisibilidad entre el contrato de prestación de servicios educacionales y el mandato otorgado para hacer cobros en el futuro, el cual por el solo ministerio de la ley se entiende revocado"73.

\section{4) DERECHO A RETENCIÓN DE PARTE DE LA MATRÍCULA}

La institución educacional, según el inciso cuarto del Art. 3 ter LPC, está facultada para retener un monto de la matrícula, que no podrá exceder al uno por ciento del arancel anual del programa o carrera, "por concepto de costos de administración”. Si bien la norma fija un límite al monto que este establecimiento puede conservar, no resuelve cómo se determina ese valor en cada caso. Eventualmente, puede quedar estipulado en el contrato de prestación de servicios educacionales, o quedar sujeto a la prueba de los gastos de operación, siempre que no exceda ese límite. En todo caso, la Corte Suprema ha declarado que la institución educacional está obligada a respetar el límite legal ${ }^{74}$.

\section{5) DERECHO A COBRAR SERVICIOS PRESTADOS}

El inciso primero del artículo $3^{\circ}$ ter permite dejar sin efecto el contrato con la respectiva institución, sin pago alguno "por los servicios educacionales no prestados". Entonces, a contrario sensu, que si entre el pago de la matrícula y el ejercicio del retracto se han prestado servicios educacionales, la institución tendrá derecho a cobrarlos. Entendemos asimismo que el hecho de que el alumno haya asistido a estas clases o charlas intermedias, no puede entenderse como renuncia del derecho de retracto.

\footnotetext{
73 Este autor distingue entre los efectos del retracto en cuanto al contrato que termina por la voluntad del retrayente y a la ineficacia que produce en los otros actos que son conexos con el acto principal. Pizarro (2005) 247.

$74 \quad$ Ver nota 37.
} 


\section{CONCLUSIONES}

1) El retracto en el contrato de educación de nivel superior es una institución original de nuestro derecho del consumidor, que, aunque no aparece suficientemente justificada en su historia legislativa, se inserta en el sistema chileno de selección de los alumnos que postulan a estudios universitarios de pregrado o a carreras técnicas, caracterizado por la libertad de los establecimientos que ofrecen esos programas para fijar sus propios procesos de postulación, y por una serie de elementos que incentivan una fuerte competencia entre ellos. El retracto educacional, entendido como un derecho que consagra la ley y como el acto jurídico mediante el cual se ejerce; tiene como titular al alumno que se ha matriculado en un centro de formación técnica, un instituto profesional o una universidad o al padre o madre o pariente cercano que ha pagado la matrícula en su favor.

2) Son requisitos para ejercer este derecho, en primer lugar, que se plantee ante la universidad, centro de formación técnica o instituto profesional con que se haya celebrado el contrato de prestación de servicios de educación superior, la ley no permite ejercer el derecho de retracto ante otro tipo de institución educativa. En segundo lugar, el retrayente debe estar matriculado en otra entidad de educación superior, de cualquier especie. Pesa sobre el mismo retrayente la carga de acreditar este hecho. No es necesario que la matrícula que se invoca en el retracto sea posterior al contrato que se pretende dejar sin efecto por la retractación. En tercer lugar, este derecho debe ejercerse en el plazo fatal de 10 días contados desde la primera publicación de los resultados de las postulaciones a las universidades pertenecientes al Consejo de Rectores. Vencido este plazo caduca la facultad de retracto y el contrato educacional nace en plenitud a la vida jurídica.

3) El retracto educacional no se explica como una condición resolutoria o ineficacia sobrevenida, ni como un incumplimiento lícito reconocido legislativamente.

4) Esta institución puede entenderse como una forma prevista por la ley para impedir que nazca un contrato, provocada por el ejercicio de una facultad que ella confiere a una de las partes, y que integra el marco jurídico en el que se forma el consentimiento de los contratantes.

5) Produce también otros efectos conexos, como hacer cesar los mandatos otorgados, dar derecho a la devolución de parte de lo pagado y de los documentos dados en garantía. Mientras da derecho al establecimiento a retener una parte de la matrícula hasta el límite legal, y a cobrar los servicios educacionales prestados en el tiempo intermedio entre la matrícula y el retracto. 


\section{BIBLIOGRAFÍA CITADA}

Aimone Gibson, Enrique (2013) Derecho de Protección al Consumidor. Santiago: LegalPublishing, 203 pp.

Badenas Carpio, Juan Manuel y Boldó Roda, Carmen (2003) Régimen Juridico de la Llamada "Venta Directa". Las Ventas Domiciliarias y a Distancia. Valencia: Tirant lo Blanch, 243 pp.

Beluche Rincón, Iris (2009) El derecho de desistimiento del consumidor. Valencia: Tirant lo Blanch, 104 pp.

Bercovitz Rodríguez-Cano, Alberto (1978) "La protección de los consumidores, la Constitución española y el derecho mercantil". Lecturas sobre la Constitución Española, Vol. 2. Madrid: Facultad de Derecho, Universidad Nacional a Distancia, pp 9-37.

Bermúdez Ballesteros, María del Sagrario (2001) "El Derecho de Desistimiento en materia de Viajes Combinados". Revista CESCO de Derecho de Consumo, $\mathrm{N}^{\circ}$ 2/2012. Centro de Estudios de Consumo. Universidad de Castilla - La Mancha. Disponible en: https://dialnet. unirioja.es/descarga/articulo/4042331.pdf

Botana García, Gema Alejandra (2001) Comercio Electrónico y Protección de los Consumidores. Colección Biblioteca de Derecho de los Negocios, Madrid: Editorial La Ley, p. 209.

Brantt Zumarán, María Graciela y Mejías Alonzo, Claudia (2013) "Artículo 3o ter". En De la Maza Gazmuri, Ińigo y Pizarro Wilson, Carlos (directores) y Barrientos Camus, Francisca (coordinadora): La Protección de los Derechos de los Consumidores, Santiago: Thomson Reuters, pp. 183-189.

Cabañas García, Juan Carlos (2005) Los procesos civiles sobre consumidores y usuarios y de control de las cláusulas generales de los contratos. Madrid: Tecnos, pp. 166 y ss.

Caprile Biermann, Bruno (2010) "El desistimiento unilateral o renuncia: una especial forma de extinción de los contratos". Estudios de Derecho Civil IV, Santiago: LegalPublishing, pp. 271-296.

Carvajal Ramírez, Patricio Ignacio (2006) "Las Arras en el Derecho Justinianeo". Revista Chilena de Derecho, Pontificia Universidad Católica de Chile, Vol. 33, N 3, pp. 529-560.

Corral Talciani, Hernán (2003) Lecciones de responsabilidad extracontractual. Santiago: Editorial Jurídica de Chile, 424 pp.

Chabas, Cécile (2002) L'inexecution licite du contrat. Paris: Bibliotheque de Droit Privé, 548 pp.

De la Maza Gazmuri, Iñigo (2010) "El suministro de información como técnica de protección de los consumidores: los deberes precontractuales de información". Revista de Derecho Universidad Católica del Norte, Año $17 \mathrm{~N}^{\circ} 2$, pp. 21-52. 
Domínguez Águila, Ramón (2009) La Prescripción Extintiva. Doctrina y Jurisprudencia. Santiago: Editorial Jurídica de Chile, 435 pp.

Estival Alonso, Luis (2006) El contrato de arras. Madrid: Difusión Jurídica y Temas de Actualidad S.A., 227 pp.

López Santa María, Jorge (2010) Los Contratos. Parte General. Santiago: Thomson Reuters, 610 pp.

López Santa María, Jorge (2002) Responsabilidad Civil por Productos. Colección Derecho de Daños. Santiago: LexisNexis.

Lorca Cisternas, Camila (2012) "Ámbito de aplicación del Derecho de Retracto en la Ley No 19.496 de Protección al Consumidor". Memoria para optar al grado de Licenciado en Ciencias Jurídicas y Sociales, Universidad Austral, inédita.

Llorente San Segundo, Inmaculada (2013) "La adaptación de la normativa reguladora del derecho de desistimiento a las exigencia de la Directiva 2011/83/UE sobre derechos de los consumidores". Cuadernos de Derecho Transnacional (octubre 2013), Vol. 5, No 2, pp. 371-397.

Momberg Uribe, Rodrigo (2005) "El derecho de retracto en los contratos de consumo". En Corral Talciani, Hernán y Rodríguez, María Sara (editores): Estudios de Derecho Civil. Santiago: Lexis Nexis.

Momberg Uribe, Rodrigo (2013) "Artículo 1o No 1". En De la Maza Gazmuri, Ińigo y Pizarro Wilson, Carlos (directores) y Barrientos Camus, Francisca (coordinadora): La Protección de los Derechos de los Consumidores. Santiago: Thomson Reuters, pp. 3-16.

NúŃEz RodrígueZ, Erick (2012) "El derecho de desistimiento: Especial consideración al desistimiento contractual". Salamanca: Colección de tesis de derecho privado. Universidad de Salamanca. Disponible en: http://hdl.handle.net/10366/121398

Pérez SÁnchez, José Antonio (2009) "El derecho de desistimiento en la legislación de consumo. Especial consideración a los contratos de índole turística”. U. de Santiago de Compostela.

Pinochet Olave, Ruperto (2013) "Artículo 3o bis". En De la Maza Gazmuri, Ińigo y Pizarro Wilson, Carlos (directores) y Barrientos Camus, Francisca (coordinadora): La Protección de los Derechos de los Consumidores. Santiago: Thomson Reuters, pp. 167-175.

Pizarro Wilson, Carlos (2005) "El incumplimiento lícito del contrato por el consumidor: "el Derecho de Retracto". En De la Maza Gazmuri, Ińigo y Pizarro Wilson, Carlos (coordinadores): Consumidores. Santiago: Abeledo Perrot, pp. 235-247.

Prado López, Pamela (2003) "Artículo 3o bis". En De la Maza Gazmuri, Ińigo y Pizarro Wilson, Carlos (directores) y Barrientos Camus, 
Francisca (coordinadora): La Protección de los Derechos de los Consumidores. Santiago: Thomson Reuters, pp. 152-164.

Puga Vial, Juan Esteban (2005) El Acto de Comercio. Crítica a la Doctrina Tradicional. Santiago: Editorial Jurídica de Chile, 266 pp.

Rolando M., Rodrigo; Salamanca V., Juan y Aliaga Q., Marcelo (2010) "Evolución de la Matrícula de Educación Superior en Chile. Periodo 1990-2009". Estudio publicado por SIES, División de Educación Superior, Ministerio de Educación, Santiago.

Rosas Zambrano, Marco Antonio (2014) "Posibilidad de dejar sin efecto el contrato en la Ley del Consumidor". Cuadernos de Análisis Jurídico, Colección de Derecho Privado VIII. Condiciones Generales de la Contratación y Cláusulas abusivas. Santiago: Ediciones Universidad Diego Portales, pp. 243-258.

Rosso Elorriaga, Gian Franco (2008) "El Contrato de Educación Superior". En Guzmán Brito, Alejandro (editor científico): "Colección de Estudios de Derecho civil en homenaje a la profesora Inés Pardo de Carvallo". Valparaíso: Ediciones Universitarias de Valparaíso.

Sandoval López, Ricardo (2004) Derecho del Consumidor. Protección del consumidor en la ley $N^{o}$ 19.496, de 1997 modificada por la ley $N^{o}$ 19.955, de 14 julio de 2004, y en la legislación comparada. Santiago: Editorial Jurídica de Chile, 247 pp.

Stitchkin Branover, David (1944) "El Mandato Civil". Revista de Derecho, U. de Concepción, Año XII, No 49.

Zurilla Cariñana, María Ángeles (2008) "Alcance y límites de la armonización del derecho de desistimiento en el texto refundido de la ley general para la defensa de consumidores y usuarios, en "Comentarios a la Ley de Consumidores". Centro de Estudio de Consumo, Universidad de Castilla - La Mancha. Disponible en: https://www.uclm.es/centro/cesco/pdf/comentarios/11.pdf

Zuloaga Ríos, Isabel Margarita (2006) Teoría de la Responsabilidad Precontractual. Aplicaciones en la formación del consentimiento de los contratos. Santiago: LexisNexis. 